\title{
La ordenación sanitaria y la Hacienda General del País Vasco: el marco jurídico público del sistema sanitario vasco
}

\author{
José Antonio Arratibel Arrondo \\ Letrado \\ Gobierno Vasco/Eusko Jaurlatitza
}

\begin{abstract}
Sumario: PLANTEAMIENTO. I. LA FINANCIACIÓN SANITARIA VASCA. I.1. Regularización de los flujos financieros entre el País Vasco y el Estado. II. EL RÉGIMEN JURÍDICO DEL ENTE PÚBLICO DE DERECHO PRIVADO OSAKIDETZA. II.1. Normas contenidas en la LOSE. II.2. Normas contenidas en los Estatutos Sociales. III. LOS LÍMITES DE LA HACIENDA GENERAL DEL PAÍS VASCO. III.1. Patrimonio. III.2. El régimen presupuestario. III.3. El control del presupuesto. III.4. Contratación Pública. III.5. Régimen de Tesorería, Finanzas y Contabilidad. III.6. Cuestiones fiscales. IV. CONCLUSIÓN.
\end{abstract}

\section{PLANTEAMIENTO}

El Gobierno Vasco inició el 23 de junio de 1993 un Plan Estratégico en el área sanitaria, más conocido como Osasuna Zainduz-Estratégias de cambio para la Sanidad Vasca, respaldado por el Parlamento Vasco ${ }^{1}$. Finalizado el periodo de reflexión del Plan, el Parlamento Vasco ha aprobado la Ley 8/1997, de 26 de junio, de ordenación sanitaria de Euskadi, en adelante LOSE, (BOPV n. ${ }^{\circ}$ 138), basada en la consideraciones nacidas del Plan Estratégico. Esta Ley se configura, entre otras cosas, como uno de los instrumento para hacer frente a la crisis del Estado Social en la prestación de la asistencia sanitaria, como ya he planteado en otros trabajos ${ }^{2}$.

\footnotetext{
${ }^{1}$ En relación alas estrategias planteadas al Parlamento Vasco puede consultarse «Osasuna Zainduz. Estrategias de cambio para la Sanidad Vasca.» Ed. Servicio Central de Publicaciones del Gobierno Vasco. Vitoria-Gasteiz, 1993.

${ }^{2}$ Esta temática la he tratado en los siguientes trabajos: (J. ARRATIBEL ARRONDO, «La nueva ordenación sanitaria de Euskadi como medida frente a la crisis de la administración prestacional y de financiación del gasto sanitario», en la Revista Jurídica La Ley, n. ${ }^{\circ}$ 4540, AÑO XIX. Sección doctrina. Madrid.1998; «Euskadiko Osasun Antolamenduari buruzko 8/1997 Legea: osasun gastua eta Ongizate estatuaren egonkortasuna», en Revista Jurídica Euskal Legelarien Aldizkaria de la Sociedad de Estudios Vasco-Eusko Ikaskuntza n. ${ }^{\circ}$ 3. San Sebastián-Donostia 1998; El marco jurídico sanitario vasco como respuesta a la crisis del Estado de Bienestar: ordenación y control del gasto sanitario», en Revista Derecho y Salud. Asociación de Juristas de la Salud. Barcelona, 1999; «Euskal osasun-sistemaren finantzaketa, aurrekontua eta kontrol ekonomikoaren azterketa:osasun antolamenduari buruzko 8/1997 Legearen irakurketa», en Revista Vasca de Administración Pública, n. ${ }^{\circ}$ 52 (setiembre-diciembre), 1998).
} 
La LOSE constituye un instrumento fundamental respecto al desarrollo y aplicación de un derecho tan relevante en el Estado Social como el relacionado con la protección y el cuidado de la salud.

La aprobación por el Consejo de Gobierno Vasco de los Estatutos Sociales del Ente Público Osakidetza-Servicio Vasco de Salud constituye la actuación definitiva para poner en marcha la nueva entidad creada en la LOSE. Con la aprobación de los Estatutos Sociales en virtud del Decreto 255/1997, de 11 de noviembre, por el que se establecen los Estatutos Sociales del Ente Público Osakidetza-Servicio vasco de salud se dictó la primera disposición de desarrollo de la LOSE y probablemente una de las más importantes manifestaciones que deberán existir para plasmar sus postulados de política sanitaria.

La configuración completa de la nueva Entidad Pública supone la delimitación última de los detalles y opciones con los que se afronta el objetivo que fundamentalmente ha presidido la reforma, esto es, el cambio del modelo de gestión de nuestros servicios públicos sanitarios. Asimismo se evidencia con soluciones concretas la intención de perseverar en la idea de reforzar el modelo público y universal con que cuenta la Sanidad Vasca.

Estos Estatutos concretan, en definitiva, la apuesta de la LOSE hacia el cambio del marco y de las herramientas de gestión, haciéndose patentes en las nuevas reglas de organización y funcionamiento de los servicios sanitarios los criterios de flexibilidad, autonomía y responsabilidad que requieren los profesionales sanitarios y los centros u organizaciones en que trabajan, para poder realizar una gestión eficiente de los recursos y poder facilitar realmente a la ciudadanía una respuesta sanitario- asistencial de auténtica calidad.

De conformidad con la LOSE, el Ente Público Osakidetza-Servicio Vasco de Salud es el Ente Institucional de la Comunidad Autónoma, de naturaleza pública y bajo la calificación de Ente Público de Derecho Privado, cuyo objeto o finalidad es la provisión de servicios sanitarios a través de las organizaciones públicas de servicios sanitarios dependientes del mismo.

La aparición de nuevas formas de gestión de la sanidad pública se ha caracterizado por la introducción de elementos propios de la gestión privada. Para tal fin se han elaborado un entramado jurídico que afecta no sólo a la Sistema INSALUD o al Sistema de alguna CA como la Vasca, sino que se ha extendido a todo el Sistema Nacional de Salud. La ausen- 
cia de criterios doctrinales y jurisprudenciales respecto a la naturaleza jurídica de estos nuevos entes, como el Ente Público de derecho Privado (EPDP) Osakidetza/Servicio Vasco de Salud, ha provocado una situación vacilante en distintos ámbitos doctrinales y jurisprudenciales. En definitiva ha provocado una primera confusión en los operadores del derecho que poco apoco se va reconduciendo.

En unos casos, la doctrina ha determinado que estamos ante una actividad sujeta al derecho privado de manera que quedan sustraídas todas las prerrogativas propias del Derecho Público ${ }^{3}$.

Del mismo modo, la jurisprudencia ha caído en la misma tentación, llevada seguramente por una interpretación restrictiva de la compleja normativa de la Comunidad Autónoma del País Vasco, al respecto ${ }^{4}$.

A nuestro juicio, todas estas vacilaciones demuestran las dificultades que están creando las nuevas fórmulas de gestión del Sistema Nacional de Salud alejadas de las tradicionales formas de la gestión de la cosa pública ${ }^{5}$.

\footnotetext{
3 Revista «Diario Médico» de fecha 2-IX-1996 y en especial «Diario Médico de 9-II-1999, p. 10. Tanto la Revista como la defensa del Colegio de Médicos de Bizkaia entienden que « Aunque el SVS/Osakidetza había estado tradicionalmente exento de estos requisitos (se refiere a los beneficios de justicia gratuita) -como cualquier otra Administración Pública- porque la Ley de Procedimiento Laboral así lo concede al Estado, las Comunidades Autónomas, las Entidades Locales y los Organismos Autónomos, una Ley de 1997 ordenó extinguir el organismo autónomo Servicio Vasco de Salud y crear en su lugar un ente público de derecho privado. Esa misma Ley declaró que el nuevo ente público en lo referente a su régimen económico hacendístico-financiero, a si régimen de organización y funcionamiento interno y a sus relaciones jurídicas externas se sujetará al derecho privado. Aunque se mantenga la titularidad del ente, su sometimiento al derecho privado implica que no goza del beneficio de justicia gratuita, por lo que ha de constituir depósito para recurrir y consignar el importe de la condena decidida por la resolución de instancia. Así, devuelve el recurso al juzgado y se niega a entrar en el fondo del asunto hasta que el Servicio Vasco de salud no cumpla con estos requisitos».

${ }^{4}$ En este sentido destacamos el Auto de la Sala de los Social del TSJPV de 13/7/1999, en relación a la STSJPV de 14 de junio de 1999 (recurso n. ${ }^{\circ}$ 125/99), que en un plazo de un mes elimina su F.J. n. ${ }^{\circ} 3$, que hacía referencia a que el EPDP Osakidetza/SVS no goza del beneficio de justicia gratuita, en los siguientes términos: " el Servicio vasco de salud tiene transferidas para esta Comunidad Autónoma las competencias del Instituto Nacional de la salud, que por constituir una entidad gestora de la Seguridad Social goza del beneficio de justicia gratuita, por lo que no procede la imposición de costas del recurso». La parte dispositiva del Auto señal, en consonancia, que «La sala Acuerda, aclarar la sentencia de este Tribunal de 14 de junio de 1999 en le sentido de eliminar el Fundamento de derecho Tercero, y la imposición de pago de costas al Servicio vasco de salud que figura en le Fallo de la citada Sentencia. (...)».

${ }^{5}$ La problemática planteada por la jurisprudencia del Tribunal Superior de Justicia del País Vasco las he tratado en otros trabajos de investigación como: J. A. Arratibel ArRondo y $\mathrm{M}^{\mathrm{a}} \mathrm{S}$. GómeZ DE ARIAN, «La aplicación de la prerrogativas jurisdiccionales en el proceso laboral a Entes Institucionales Sanitarios: el caso del Servicio Vasco de Salud-Osakidetza», en la Revista Jurídica La Ley, n. ${ }^{\circ}$ 4968, AÑO XXI. Sección doctrina. Madrid, 2000.
} 
Por tanto, para responder a las cuestiones planteadas se hace imprescindible el análisis en profundidad del régimen jurídico general de las normas que regulan los Entes Públicos de Derecho Privado en el Sistema Nacional de Salud así como en el propio de la CAPV. No obstante, advertimos que este trabajo se centrará fundamentalmente en el sistema sanitario vasco regulado por la normas generales del Decreto Legislativo 1/1997, de 11 de noviembre, por el que se aprueba el texto refundido de las disposiciones legales vigentes sobre Principios Ordenadores de la Hacienda General del País Vasco, (en adelante LPOHG), así como la norma específica de creación del EPDP Osakidetza/SVS (LOSE y sus normas de desarrollo).

No obstante, avanzamos que hay que tener presente como señala BORRAJO, que,

«no se puede confundir la forma (ya sea de ente de Derecho público, ya de ente de Derecho privado), con el sustrato real de la organización que se encuentra debajo, y a la cual sirve la vestidura o el ropaje jurídico que se pone sobre ella. Obviamente la Administración pública, los poderes públicos, las organizaciones financiadas con fondos públicos, serán Administración pública o serán entes financiados con fondos públicos, completamente al margen de que se les someta, formalmente, a normas de Derecho privado, al Código civil, al Código de comercio, al Estatuto de los trabajadores; o que se les someta a leyes de Derecho administrativo, tales como la Ley de Contratos del Estado o la legislación de funcionarios. Además, junto al dato sociológico inesquivable de que cuando actúan un conjunto de funcionarios o de personas que dependen del presupuesto público, al que acceden en virtud de mecanismos ajenos al derecho de propiedad, como la elección o el nombramiento, y que tienen una determinada cultura, una determinada percepción de su misión y unos determinados medios, que respaldan y que modulan su actuación, son Administración pública; junto a ese dato, se agolpan una serie de parámetros jurídicos que no pueden ser olvidados.

En la actualidad, la distinción tajante entre el Derecho público y el Derecho privado en nuestro ordenamiento se está suavizando, hasta caso desaparecer en determinados ámbitos. Junto a los fenómenos clásicos de interrelación, propiciados por el intervencionismo público en las esferas social y económico, se está produciendo un fenómeno creciente de relativización de las formas jurídicas tradicionales del siglo XIX. Fenómeno acicateado por el Derecho comunitario europeo, cuyas normas -por ejemplo en materia de contratación administrativa, o de ayudas estatales- se aplican uniformemente a sistemas jurídicos muy diversos y, por ende, prescindiendo de las formas jurídicas establecidas por cada uno de los Derechos nacionales singulares. Igualmente, nuestra Constitución sólo distingue entre poderes públicos y ciudadanos, sin que aquéllos puedan transmitarse en ciudadanos por muchos ropajes privadas que adopten». ${ }^{6}$

${ }^{6}$ I. BorRajo InIESTA, « La huida hacia fórmulas de gestión de Derecho Privado en la prestación e Servicios sanitarios: la supuesta crisis del Derecho Administrativo» en Tercer Congreso de Derecho y Salud bajo el título de la Gestión de los Servicios sanitarios: Modelos Alternativos. Ed. Gobierno de Navarra, Departamento de Salud, p. 105. 


\section{LA FINANCIACIÓN SANITARIA VASCA}

La transferencia presenta una especificidad en la CAPV en relación a los gastos sociales. Hay que recordar que, el 1 de enero de 1988 Euskadi asumió las competencias en materia de Asistencia Sanitaria y Asistencia social, prestadas por el INSALUD y el INSERSO. Estas competencias corresponden a las Instituciones Comunes de la Comunidad Autónoma en el caso del INSALUD y a los Órganos Forales de los Territorios Históricos en el caso del INSERSO (exceptuando un 2,22\% que corresponde a las Instituciones Comunes). Los Reales Decretos 1536/87 y 1476/87, de traspaso de las funciones y servicios de ambos institutos, establecen un mecanismo de financiación dual de acuerdo con las dos grandes fuentes de ingresos de cada una de las entidades: las aportaciones del Estado con cargo a sus Presupuestos Generales y las cotizaciones sociales y otros ingresos. El importe inicial a financiar resulta de la aplicación del índice de imputación $(6,24 \%)$ sobre el total inicial del Presupuesto de cada entidad, una vez efectuados algunos ajustes de escasa cuantía.7Una vez establecidos para cada entidad los porcentajes sobre el total que significa cada fuente de financiación, porcentajes que permanecen fijos para todo el ejercicio, incluso en la liquidación, la parte de la financiación del traspaso correspondiente a las aportaciones del Estado se realiza vía minoración del cupo y aquella referida a las cotizaciones sociales vía transferencias al País Vasco de la Tesorería General de la Seguridad Social (transferencias mensuales por doceavas partes) ${ }^{8}$.

Asimismo, según los apartados G.10 de ambos Reales Decretos de traspaso, el País Vasco participará, en concepto de anticipos a cuenta de la liquidación y conforme al índice de imputación (6,24\%), de las ampliaciones e incorporaciones de créditos aprobadas en el ejercicio corriente para el INSALUD y el INSERSO. De forma que estos anticipos se computan en los plazos inmediatamente posteriores de pago del Cupo y transferencia de la Tesorería General. La liquidación de la financiación de las competencias asumidas en estas materias está totalmente ligada al grado de ejecución presupuestaria de ambos institutos, resultando, en el mejor de los casos, una diferencia nula en liquidación cuando el grado de ejecu-

\footnotetext{
7 Hacen referencia a la parte no asumida del Fondo de Investigaciones Sanitarias, ingresos por servicios a terceros, amortizaciones, costes indirectos asociados al traspaso, etc.

${ }^{8}$ Hago referencia a estas cuestiones en mi trabajo J.A. ARRATIBEL ARrondo, «Euskal Herriogasuntza Nagusiaren finantzaketarako arazoak: irtenbide juridiko baten azterketa»,/(«La problemática de la finnaciación de la Hacienda General del País Vasco: estudio de una solución jurídica.»). Ed. Sociedad de Estudios Vascos-Eusko Ikaskuntza. Revista jurídica ELERIA, n. ${ }^{\circ}$ 1, 1997, pp. 5 a 19.
} 
ción es del 100\% a favor del Estado en caso de que fuese inferior. La liquidación definitiva del importe a financiar, una vez cerrado el ejercicio, se produce a partir de las obligaciones reconocidas por el INSALUD e INSERSO, con determinadas correcciones. Se calcula el porcentaje de desviación sobre el presupuesto inicial y se aplica al importe inicial a financiar a la Comunidad Autónoma9.

Los Presupuestos iniciales del INSALUD (también INSERSO) suelen ser insuficientes para atender el creciente gasto sanitario. Ello obliga a efectuar modificaciones presupuestarias. Con independencia de las liquidaciones definitivas y, tal y como se contempla en el apartado G. 10 del $\mathrm{RD}$ de transferencias citado, a lo largo de los distintos ejercicios presupuestarios la CAPV participa en las ampliaciones de crédito aprobadas en el presupuesto del INSALUD (también INSERSO), en el importe determinado por la aplicación del índice de imputación antes citado del 6,24 \% y el porcentaje que corresponde a cada una de las vías de financiación.

En virtud del apartado G. 8 de ambos RD de Transferencia el cálculo de la liquidación se efectúa aplicando a los créditos inicialmente asignados el porcentaje d desviación que experimente en el ejercicio la ejecución de los Presupuestos del INSALUD-INSERSO no transferido a la CAPV respecto los Presupuestos iniciales.

Este sistema de Cupo ha funcionado hasta los conflictos surgidos con los sucesivos gobiernos del PP. El origen de los mismos estaba en la financiación de la Sanidad del año 2001. Para cubrir el déficit sanitario de las Comunidades Autónomas, el Estado aumentó los créditos para Sanidad. Ante esta situación las Instituciones Vascas entienden que le corresponden un porcentaje -el 6,24\%- de los créditos incrementados ya que de lo contrario se rompía los criterios que sostienen el sistema concertado.

De ahí procedía la cifra inicial, los 32 millones de euros -el 6,24\% del aumento de la financiación de la sanidad en el 2001-, una cantidad a la que el Estado entendía que Euskadi no tiene derecho por tener la sanidad transferida.

\footnotetext{
9 C. Lambarri y JZ. LarReA de J.L. VicuÑa, «El Cupo». Ed. IVAP-HAEE, Oñati, 1994, pp. 142 y ss. Me remito a anteriores trabajos de investigación: J.A. ARRATIBEL ARRONDO, «Eusko Jaurlaritzako Aurrekontuaren Finantzaketa: 1997-2001 artean Foru aldundiek egin beharreko ekarpenen araudia.» Revista Vasca de Administración Pública, n. ${ }^{\circ}$ 48, mayo-agosto 1997. También en, »Eusko Jaurlaritzako Aurrekontuaren Finantzaketa: 1997-2001 artean Foru aldundiek egin beharreko ekarpenen araudia». Revista Vasca de Administración Pública, n. ${ }^{\circ} 48$, mayo-agosto 1997. IVAP-HAEE Vitoria-Gasteiz.
} 
Al no llegar al País Vasco el dinero que pensaba que le correspondía, el Gobierno Vasco decidió en mayo del 2003 descontar los 32 millones del cheque que envió para pagar el Cupo al Estado, el pago por las competencias ejercidas por la Administración central en la Comunidad Autónoma.

A su vez, el Ministerio de Economía y Hacienda replicó en septiembre de ese año descontando el dinero del otro flujo financiero que une a ambas Administraciones: el pago por ajustes del IVA y los impuestos especiales.

Así, han seguido descontándose mutuamente la cantidad cada tres o cuatro meses hasta hoy.

La dotación presupuestaria aumentó a 52 millones por discrepancias sobre las liquidaciones sanitarias de los años posteriores y también por otras divergencias por la compensación a los ayuntamientos por la supresión del impuesto de actividades económica

\section{I.1. Regularización de los flujos financieros entre el País Vasco y el Estado}

En el marco de las medidas tributarias y financieras propuestas por la Conferencia de Presidentes celebrada el pasado 10 de septiembre, el Gobierno español reconoció y asumió el derecho del País Vasco a participar de todas aquellas dotaciones presupuestarias que con carácter extraordinario ha realizado o realice la Administración del Estado para la financiación de los gastos sanitarios de competencia de las Comunidades Autónomas, y que tal participación se lleve a cabo a través de las correspondientes minoraciones o reducciones del Cupo que el País Vasco abona al Estado.

Por su parte, la Comisión Mixta del Concierto Económico entre el País Vasco y el Estado ha acordado regularizar los flujos financieros de carácter sanitario.

Por un lado, la Comisión Mixta ha aprobado los Cupos líquidos definitivos que el País Vasco abona al Estado correspondientes a los ejercicios 2002, 2003 y 2004, así como el Cupo provisional de este año 2005.

Por otro, se ha aprobado la minoración o reducción del Cupo, por importe de 50,8 millones de Guros, correspondiente a la participación del País Vasco en las ampliaciones presupuestarias extraordinarias realizadas por el Estado para la financiación de los gastos sanitarios de competencia 
de las Comunidades Autónomas durante los ejercicios 2002 y 2003 -si bien con cargo al anterior modelo de financiación de las Comunidades de régimen común vigente en el periodo 1997-2001-.

De dicha cantidad quedan pendientes de minorar 18,6 millones de Guros, montante que será minorado o reducido en el tercer y último pago del Cupo provisional de 2005 que el País Vasco abonará a la Administración del Estado el próximo mes de diciembre.

De esta forma quedará totalmente regularizado este flujo financiero del País Vasco hacia el Estado.

Además, la Comisión Mixta del Concierto Económico ha acordado la participación del País Vasco en las eventuales dotaciones presupuestarias extraordinarias que en lo sucesivo y con idéntico objeto -financiación del gasto sanitario de las Comunidades Autónomas- realice la Administración del Estado.

\section{EL RÉGIMEN JURÍDICO DEL ENTE PÚBLICO DE DERECHO PRIVADO OSAKIDETZA}

Visto el régimen general de la Organización Institucional de la CAPV $\mathrm{y}$, en concreto las normas generales aplicables a los EPDP hemos concluido que forman parte de la Administración pública de la CAPV, tiene naturaleza pública, ejerce descentralizadamente competencias de la CAPV, se rige por el derecho privado con excepción a las normas de la Hacienda Pública y las preceptos contenidos en la Ley de creación Pero esta afirmación genérica la debemos complementar con el análisis específico de la LOSE y las normas que la desarrollan, al objeto de determinar, con mayor rigor, el régimen jurídico público o privado a que se somete cada una de sus actuaciones en el tráfico jurídico.

En este apartado, por tanto, vamos a tratar de dar contenido jurídico a lo que hemos denominado Normas Básicas de la LOSE y de los Estatutos Sociales del EPDP Osakidetza/SVS con la finalidad de aquilatar cuales son las normas del Derecho Público aplicables al EPDP y, en definitiva, afirmar que sus actuaciones corresponde a una parte de la Administración Pública Vasca a la cual se le aplican las prerrogativas que estamos analizando.

La metodología de la exposición consistirá en primer lugar acotar las normas contenidas en la LOSE, así como en le Decreto 255/1997 y el arti- 
culado de los Estatutos el EPDP en relación a sus sujeción al Derecho Público y Privado de su actividad. Seguidamente, analizaremos las facultades del EPDP sujetas al Derecho Público al mismo tiempo que recogemos la dispersa normativa aplicable a cada una de dichas facultades. En fin, obtendremos un cuadro que, como se puede comprobar por lo expuesto, determinan el conjunto de peculiaridades derivadas precisamente de su carácter de ente público que lo diferencian sustancialmente del resto de entidades netamente privadas. Es por ello que entendemos que no se puede afirmar, como lo ha dicho la doctrina y la alguna jurisprudencia, que la LOSE «declaró que el nuevo ente público en lo referente a su régimen económico hacendístico-financiero, a su régimen de organización y funcionamiento interno y a sus relaciones jurídicas externas se sujetará al derecho privado», sin precisar y ahondar más en cada una de las materias que regulan sus actuaciones.

\section{II.1. Normas contenidas en la LOSE}

El régimen jurídico al que se debe sujetar la actuación del EPDP se encuentra determinado en los siguientes disposiciones de la LOSE:

El artículo 21.1 de la LOSE que establece:

«El ente público Osakidetza-Servicio Vasco de Salud se rige por los preceptos de la presente Ley y por las disposiciones reglamentarias emanadas del Gobierno, al que corresponderá establecer sus estatutos sociales».

Por tanto, Osakidetza/SVS está sujeta a las normas contenidas en la propia LOSE y las normas que la desarrollan, especialmente, el Decreto 255/1997, de 11 de noviembre, por el que se establecen sus Estatutos Sociales.

El art. 21.2 de la LOSE define el ámbito jurídico privado/publico al que debe sujetarse su actuación. En nuestra opinión la separación de ambos ámbitos no se encuentra definida con la precisión deseable ya que hubiera sido más aconsejable listar las actuaciones del EPDP en uno u otro ámbito de actuación. De esa manera se hubiera evitado los problemas interpretativos a que ha dado lugar. En este sentido, el precepto establece con rotundidad que Osakidetza se rige por el Derecho Privado en la práctica totalidad de sus actuaciones, por no decir todas, pero de una manera indeterminada, esto es:

«En lo que se refiere a su régimen económico y hacendistico-financiero a su régimen de organización y funcionamiento interno y a sus relaciones jurídicas externas se sujetará al Derecho privado, sin perjuicio de las siguientes circunstancias: (...)». 
En este sentido, la redacción dada al precepto parece sugerir en una primera lectura que el EPDP Osakidetza/SVS se rige por le Derecho Privado en la materias más importantes como son: «su régimen económico y hacendístico-financiero, su régimen de organización y funcionamiento interno y a sus relaciones jurídicas externas». Precisamente el efecto jurídico es totalmente el contrario, ya que la coletilla «sin perjuicio de las siguientes circunstancias» va a introducir las excepciones a su actuación en régimen de Derecho Privado. Estas excepciones son tan importantes cuantitativamente como cualitativamente, como veremos, que esa primera conclusión respecto a la sujeción al Derecho Privado se desvanece cuando comprobamos que, en realidad, las actividades más importante se ven sujetas al derecho público. La redacción hubiera sido más acertada, a mi juicio, en sentido contrario, esto es, señalar las materias a las que el EPDP está sujeto al Derecho Público, o cuanto menos una lista no cerrada, y un listado de las materias sujetas a Derecho Privado.

En efecto, si nos remitimos a la lectura pausada del art. 21 de la Ley de Ordenación, podemos comprobar que no podemos concluir con una interpretación literal asilada del precepto citado ya que éste consta, además, de otros cinco párrafos, además de otros dos apartados. Lo que hace la LOSE es una remisión en cascada al ordenamiento jurídico vasco, en función de la materia de que se trate, sin determinar explícitamente lo sujeto al derecho privado o al derecho público, salvedad de las potestades administrativas. Por tanto, se impone un análisis en profundidad del ordenamiento jurídico vasco con el fin de determinar las áreas del EPDP Osakidetza sujetas a u otro ámbito del derecho y, en definitiva, sus repercusiones en la gestión de los servicios públicos sanitarios.

Así, el apartado $2^{\circ}$ del art. 21 dispone que:

a) En todo lo que corresponde a las materias propias de la Hacienda General del País Vasco, se sujetará a lo que disponga la legislación de la Comunidad Autónoma correspondiente a dichas materias en relación con los entes públicos de Derecho privado. En lo que a su control económico se refiere éste se ejercerá en la modalidad de control económico-financiero y de gestión de carácter permanente, de acuerdo con lo establecido en la Ley 14/1994, de 30 de junio, de Control económico y contabilidad de la Comunidad Autónoma de Euskadi.

b) En sus relaciones con el Departamento competente en materia de sanidad se sujetará a las disposiciones de esta ley por las que se regulan los contratos-programa. 
c) La contratación se ajustará a las previsiones que para cada personificación jurídica establezca la legislación sobre contratos de las Administraciones públicas.

d) El régimen de personal se sujetará a las disposiciones contenidas en esta ley y restantes normas de aplicación específica.

e) Las organizaciones dependientes del ente no tendrán la consideración de órganos administrativos, sin perjuicio de que deban sujetarse al régimen jurídico de los mismos en todo lo concerniente ala formación y exteriorización de sus actos cuando ejerzan potestades administrativas, conforme a las reglas que contiene el art. 21.3 que señala lo siguiente.

Es apartado $3^{\circ}$ del art. 21 de la LOSE establece que,

«El ente público Osakidetza-Servicio Vasco de Salud se sujetará al Derecho público, agotando, en su caso, sus actos la vía administrativa, cuando ejerza potestades administrativas por atribución directa o delegación, así como en cuanto a su régimen de patrimonio y en materia de responsabilidad patrimonial ante terceros por el funcionamiento de sus servicios».

A estos preceptos y a los efectos de nuestro trabajo hay que añadir lo dispuesto en el art. 24 de la LOSE en relación a la adscripción al EPDP Osakidetza/SVS de los bienes y derechos contenidos en la transferencia del INSALUD a la CAPV para gestionar la prestación de asistencia sanitaria de la Seguridad Social en el ámbito de la CAPV, es decir, asume las funciones y servicios en calidad de Entidad Gestora de la Seguridad Social, en estos términos:

«Se adscribirán al ente público Osakidetza-Servicio Vasco de Salud los bienes y derechos propiedad de la Comunidad Autónoma de Euskadi para el cumplimiento de la finalidad que tiene encomendada. Ello se entenderá sin perjuicio de la adscripción del patrimonio de la Seguridad Social referido en las regulaciones correspondientes sobre traspaso de funciones y servicios a la Comunidad Autónoma de Euskadi».

\section{II.2. Normas contenidas en los Estatutos Sociales}

La aprobación por el Consejo de Gobierno Vasco de los Estatutos Sociales del Ente Público Osakidetza-Servicio vasco de salud constituye la actuación definitiva para poner en marcha la nueva entidad creada en la Ley 8/1997, de 26 de junio, de Ordenación sanitaria de Euskadi. Con la aprobación de los Estatutos Sociales en virtud del Decreto 255/1997, de 11 de noviembre, por el que se establecen los Estatutos Sociales del Ente Público Osakidetza-Servicio vasco de salud se dictó la primera disposición de desarrollo de la Ley de Ordenación sanitaria y probablemente una 


\section{A) Principios organizativos}

De conformidad con el art. 20 de la LOSE, el Ente Público Osakidetza-Servicio vasco de salud es el Ente Institucional de la Comunidad Autónoma, de naturaleza pública y bajo la calificación de Ente Público de Derecho Privado, cuyo objeto o finalidad es la provisión de servicios sanitarios a través de las organizaciones públicas de servicios sanitarios dependientes del mismo. Es por tanto, la forma organizativa de la CAPV que asume las competencias transferidas del INSALUD a

${ }^{10}$ La estructura de este Decreto consta de un artículo único que dispone la aprobación de los estatutos del ente, de conformidad con »el texto articulado que se adjunta en Anexo I» tres disposiciones Adicionales y dos disposiciones finales. El texto articulado contiene los Estatutos sociales del ente en una veintena de artículos. La Disposición Adicional Primera. Establece el inicio de actividades por el Ente Público el 1 de enero de 1998, produciéndose en la misma fecha la extinción del Organismo Autónomo, de acuerdo con lo dispuesto en la Ley 8/1997, de 26 de junio, de Ordenación sanitaria de Euskadi. A la entrada en vigor del Decreto se procedió a la constitución del Consejo de Administración del Ente Público, que desarrolla las funciones previstas en los Estatutos Sociales y asumirá las que correspondan al Consejo de Administración del Organismo Autónomo hasta dicha fecha. Asimismo se procedió al nombramiento del Director General y de los Directores de División de la organización central del Ente Público, quienes desarrollan las funciones previstas en los Estatutos Sociales y asumirán las que correspondan a los órganos centrales de dirección del Organismo Autónomo conforme determine el Consejo de Administración del Ente Público. La disposición adicional segunda dispone las Operaciones pendientes del extinto Organismo autónomo. Se autoriza a los órganos directivos de gestión en el Ente Público Osakidetza-Servicio vasco de salud, así como a los órganos respectivos del Departamento de Hacienda y Administración Pública, de acuerdo con los criterios que señale este último, para que continúen en sucesivos ejercicios, hasta su finalización correspondiente, la tramitación de cuantos expedientes y operaciones de gestión económico-financiera se encuentren pendientes a la fecha de extinción efectiva del Organismo Autónomo Osakidetza-Servicio vasco de salud. La Diposición adicional tercera concreta el modelo de Control económico-financiero y de gestión del Ente Público Osakidetza-Servicico vasco de salud previsto en la Ley 871997. El control financiero permanente sobre la actividad del Ente Público Osakidetza-Servicio vasco de salud previsto en el artículo 21 de Ley 8/1997, de 26 de junio, de Ordenación sanitaria de Euskadi, se llevará a cabo de conformidad con el artículo 12 del Decreto 464/1995, de 31 de octubre, por el que se desarrolla el ejercicio del control económico interno y la contabilidad en el ámbito de la Administración Pública de la Comunidad Autónoma de Euskadi, por la Intervención en Osakidetza-Servicio vasco de salud, la cual ejercerá sus funciones en nombre y por delegación del Director de la Oficina de Control Económico. La Intervención en Osakidetza-Servicio vasco de salud tendrá nivel orgánico de Dirección estando adscrita orgánicamente a la Dirección General del Ente Público y funcionalmente a la Oficina de Control Económico, y su titular, llamado Interventor en Osakidetza-Servicio vasco de salud, será nombrado por el Gobierno a propuesta del Consejero de Hacienda y Administración Pública. El personal requerido para ejercer dichas funciones de control financiero permanente pertenecerá a la estructura y plantilla de la Oficina de Control Económico y estará presupuestado en los programas de esta última. 
la que se le encomienda gestionar la prestación de la asistencia sanitaria de la Seguridad Social.

\section{B) Fines}

En desarrollo de su objeto, el Ente Público Osakidetza-Servicio vasco de salud perseguirá a través de todas sus organizaciones los fines de interés general que a continuación se enumeran:

a) Ejecutar la provisión del servicio público sanitario en la Comunidad Autónoma de Euskadi mediante las prestaciones de asistencia primaria y especializada que sean objeto de aseguramiento y contratación pública, así como mediante su participación en los programas públicos que se establezcan de promoción de la salud, prevención de enfermedades, asistencia sanitaria y rehabilitación. Asimismo podrá participar, en las condiciones que se establezcan, en programas de asistencia sociosanitaria.

b) Proporcionar a las personas que accedan a sus servicios las condiciones necesarias para el pleno ejercicio de sus derechos y deberes de carácter instrumental o complementario, promoviendo especialmente la mejora continua de los niveles de información, la personalización en la atención y la calidad de la misma.

c) Promover la docencia en ciencias de la salud, así como las actividades de investigación, estudio y divulgación relacionadas con las mismas, de acuerdo con las líneas estratégicas y programas que establezca el Departamento de Sanidad y con la colaboración que se establezca con Universidades y demás instituciones competentes en la materia.

d) Promover la formación y actualización de los conocimientos especializados que requiere su personal sanitario y no sanitario, tanto en el campo específico de la salud como en los de la gestión y administración sanitarias.

e) Promocionar el desarrollo de sus recursos sanitarios a través de acciones y programas propios o en colaboración con otras instituciones, y cualquier otro fin relacionado con su objeto que se acuerde por el Consejo de Administración del Ente Público. 


\section{C) Personalidad jurídica y capacidad de obrar}

De conformidad con lo dispuesto en el Decreto Legislativo 1/1997, de 11 de noviembre, por el que se aprueba el Texto Refundido de la Ley de Principios Ordenadores de la Hacienda General del País Vasco y en la Ley de Ordenación sanitaria de Euskadi, el Ente Público Osakidetza-Servicio vasco de salud dispone de personalidad jurídica pública diferenciada y plena capacidad de obrar para el cumplimiento de su objeto y fines. Esta plena capacidad de obrar se encuentra «limitada» a la tutela que determine el ordenamiento jurídico en función de su adscripción al Departamento de Sanidad en la Administración de la Comunidad Autónoma de Euskadi.

Hasta la fecha las organizaciones de servicios que constituyen el Ente no disponen de personalidad jurídica propia. Cuando esta se otorgue ostentarán la capacidad que corresponda a las facultades de gestión que tengan expresamente atribuidas, tanto en estos Estatutos como a través de los acuerdos adoptados por los órganos rectores correspondientes del Ente $^{11}$.

${ }^{11}$ En Anexo II al presente Decreto se determinan las organizaciones de servicios del Ente Público Osakidetza-Servicio vasco de salud que se entenderán constituidas a la fecha de inicio de sus actividades. En lo sucesivo, se podrán reorganizar los recursos adscritos al Ente Público mediante la modificación, fusión o segregación de las organizaciones de servicios existentes, pudiéndose adoptar dichas medidas por acuerdo del Consejo de Administración del Ente Público y de acuerdo con lo que al efecto dispone el artículo 22.2 de la Ley de Ordenación sanitaria de Euskadi. Este Anexo establece tres ámbitos territoriales en relación a las organizaciones de servicios: ÁMBITO TERRITORIAL DE LA COMUNIDAD Autónoma: 1.- Dirección General, Ente Público Osakidetza-Servicio vasco de salud. * Dispone de Tesorería propia desde el inicio de actividades del Ente. 2.- Emergencias (Unidades Territoriales de Emergencias). 3.- Centro Vasco de Transfusiones y Hemoderivados. 4.- OSATEK-Tecnología Sanitaria de Euskadi, S.A. * Sociedad Pública cuyo capital es de titularidad única del Ente Público Osakidetza-Servicio vasco de salud. ÁMBITO TERRITORIAL DEL ÁREA DE SALUD DE ARABA: 1.Hospital Txagorritxu. * Dispone de Tesorería propia desde el inicio de actividades del Ente. 2.- Hospital Santiago. * Dispone de Tesorería propia desde el inicio de actividades del Ente. 3.- Hospital Leza. 4.- Hospital Psiquiátrico y Salud Mental Extrahospitalaria de Araba. 5.- Comarca Araba. ÁMBITO TERRITORIAL DEL ÁREA DE SALUD DE BIZKAIA: 1.- Hospital Cruces. * Dispone de Tesorería propia desde el inicio de actividades del Ente. 2.- Hospital Basurto. * Dispone de Tesorería propia desde el inicio de actividades del Ente. 3.- Hospital Galdakao. * Dispone de Tesorería propia desde el inicio de actividades del Ente. 4.- Hospital San Eloy. * Dispone de Tesorería propia desde el inicio de actividades del Ente. 5.- Hospital Santa Marina. 6.- Hospital Gorliz. 7.- Hospital Bermeo. 8.- Hospital Zaldibar. 9.- Hospital Zamudio. 10.- Salud Mental Extrahospitalaria de Bizkaia. 11.- Comarca Bilbao. 12.- Comarca Interior. 13.- Comarca Uribe-Kosta. 14.- Comarca Ezkerraldea-Enkarterri. ÁMBITO TERRITORIAL DEL ÁREA DE SALUD DE GIPUZKOA: 1.- Complejo Hospitalario de Donostia. Hospital de Aranzazu. Dispone de tesorería propia desde el inicio de las actividades del Ente. 3. Hospital de Gipuzkoa. Dispone de tesorería propia desde el inicio de las actividades del Ente. 4. Hospital de amara. 5. Hospital de Zumarraga. 6. Hospital Bodasoa. 7. Hospital de Mendaro. Dispone de tesorería propia desde el inicio de las actividades del Ente. Salud Mental extrahospitalaria de Gipuzkoa. 10. Comarca Gipuzkoa-este. 11. Comarca Gipuzkoa-oeste. 
Corresponde al Gobierno Vasco, mediante Decreto, crear organizaciones de servicios del Ente Público Osakidetza-Servicio vasco de salud dotadas de personalidad jurídica propia. En este caso, el Decreto de creación y las correspondientes normas estatutarias podrán establecer las especificaciones que procedan sobre su capacidad de obrar y el régimen de gestión de la entidad en función de la figura jurídico organizativa de que se trate, quedando sujetas en todo caso a los presentes Estatutos en todo lo concerniente a su dependencia del Ente Público y a las facultades generales que se atribuyen a los órganos rectores del mismo.

\section{D) Normas sobre régimen jurídico}

En primer lugar, con este nomen únicamente el art. 5 de los Estatutos Sociales establece dos tipos de normas: La primeras hacen referencia al régimen jurídico general aplicable al Ente Público Osakidetza-Servicio vasco de salud comprende las normas que establece la Ley de Ordenación sanitaria de Euskadi, los presentes Estatutos Sociales y cuantas Leyes y Disposiciones de carácter general resulten aplicables a los Entes Públicos de Derecho Privado de la Comunidad Autónoma de Euskadi. No despeja ninguna duda respecto a lo establecido en el art. 21.1 de la LOSE.

En segundo lugar, respecto a la fijación de las normas de sujeción al derecho público y privado de la actividad del EPDP Osakidetza/SVS únicamente desarrolla el art. 21.2 e) y el 21.3 de la LOSE en relación a las potestades administrativas del EPDP Osakidetza/SVS.

Por último, el resto de aspectos contenidos en el art.21 de la LOSE se encuentran desarrollados a los largo del articulado de los Estatutos Sociales, y en especial, el capítulo V relativo al Régimen de Gestión esto es: Normas sobre régimen patrimonial, normas sobre régimen presupuestario, financiero y contable, normas sobre el régimen de tesorería, normas sobre régimen orgánico de contratación. A ello se une la disposición adicional tercera del cuerpo del Decreto 225/1997 relativo al control económicofinanciero y de gestión del ente público Osakidetza/SVS.

\section{LOS LÍMITES DE LA HACIENDA GENERAL DEL PAÍS VASCO}

El artículo 21.2 de la LOSE que establece: 


\begin{abstract}
«En lo que se refiere a su régimen económico y hacendístico-financiero a su régimen de organización y funcionamiento interno y a sus relaciones jurídicas externas se sujetará al Derecho privado, sin perjuicio de las siguientes circunstancias:
\end{abstract}

1. En todo lo que corresponde a las materias propias de la Hacienda General del País Vasco, se sujetará a lo que disponga la legislación de la Comunidad Autónoma correspondiente a dichas materias en relación con los entes públicos de Derecho privado.

2. En lo que a su control económico se refiere éste se ejercerá en la modalidad de control económico-financiero y de gestión de carácter permanente, de acuerdo con lo establecido en la Ley 14/1994, de 30 de junio, de Control económico y contabilidad de la Comunidad Autónoma de Euskadi.

Llama la atención que el art.21.2 de la LOSE haga un diferenciación entre las materias propias de la Hacienda General del País Vasco y el sistema de control. Decimos esto porque el sistema de control también integra el listado de materias que integran la Hacienda General. De ahí que pueda parecer equívoco e incluso defíciente en cuanto a técnica legislativa, salvo que se hubiera querido determinar con mayor precisión el sistema de control a ejercer. De todas formas entiendo que resulta redundante ya que la propia norma que regula el Control Contabilidad de la CAPV establece el tipo genérico de control para los EPDP.

Del mismo modo llama la atención que el art. 21.2 c) haga referencia expresa a la contratación ya que, también, es una de las materias propias de la Hacienda General del País Vasco, contemplada en el art. 1.2c) de la LPOHG. En esta exposición vamos a tratar la contratación como materia propia de la Hacienda General y la analizaremos en este apartado.

En definitiva lo que hace la LOSE es una remisión a las normas contenidas en el Decreto Legislativo 1/1997, de 11 de noviembre, por el que se aprueba el texto refundido de las disposiciones legales vigentes sobre Principios Ordenadores de la Hacienda General del País Vasco, (LPOHG). Recordemos que el art.1.2 de la LPOHG separó formalmente la regulación jurídica de cada una de las materias que componen la Hacienda General, es decir:

- el régimen del Patrimonio,

- el régimen presupuestario,

- el régimen de control y contabilidad,

- el régimen de contratación,

- la Tesorería, 
- la regulación de los tributos propios e ingresos de derecho público y privado,

- el endeudamiento,

- la concesión de garantías.

- el régimen de prerrogativas de la Comunidad Autónoma en relación a las demás materias de la hacienda general.

- cualquier otra relacionada con los derechos y obligaciones de naturaleza económica de que sea titular la Comunidad Autónoma de Euskadi.

En este sentido, estamos de acuerdo con la síntesis que ofrece VILLAR, respecto al proceso de conversión de la autoridad sanitaria en una entidad pública instrumental, con personalidad y patrimonio propios, que sujeta su actividad externa al derecho privado y, en concreto del caso de Osakidetza. Dice que la LOSE intenta separar las funciones que, por suponer ejercicio de potestades, quedan sometidas al derecho administrativo, de aquellas otras que pueden realizarse de conformidad con las normas jurídico-privadas.

Se refiere a este 21 de la LOSE « que si bien declara con carácter general la sujeción del ente público Osakidetza-Servicio Vasco de Salud al Derecho Privado en cuanto a su régimen económico, hacendístico-financiero, organización y funcionamiento interno y relaciones jurídicas externas, somete al Derecho Público las cuestiones referidas a la Hacienda General del País Vasco, las relaciones con el Departamento de Sanidad, la contratación según las previsiones de la legislación básica del Estado, el régimen de personal, y en general cuando ejerza potestades administrativas, patrimonio y en materia de responsabilidad patrimonial ante terceros por el funcionamiento de sus y se rijan por un sistema económico contable privado, que les asegura un grado notable de autonomía en la gestión. No obstante, plantea que la LOSE que tal separación deja interrogantes sin respuesta, por ejemplo la responsabilidad patrimonial frente a terceros del Servicio Vasco de Salud. El problema es si este régimen alcanza también a su actividad prestacional a través de terceros, bien mediante entidades instrumentales, bien por concierto sanitario, o, por ser una excepción al régimen privado general, quedan fuera de esa clase de responsabilidad -con independencia de los mandatos constitucionales y legales sobre esta materia-. Con todo, esta separación entre público y privado en sanidad encaja con la distinción entre el régimen básico del servicio y sus modos de gestión y, con ello, se reduce el riesgo más grave de la conocida huida al derecho privado: el de una empresa mercantil dictando actos administrativos $^{12}$.

12 F. Villar Rojas; «La Ley de hacilitación de nuevas formas de gestión del Sistema nacional de Salud: ¿Hacia la desregulación de la Sanidad Pública? O. c. p. 79. Analiza también esta misa cues- 
Seguidamente vamos a analizar las normas que rigen las materias propias de la Hacienda General del País Vasco con el fin de determinar: en primer lugar, las normas que le son aplicables al Servicio Vasco de Salud (Derecho Público/Privado; en segundo lugar, determinar las prerrogativas administrativas que detenta en cuanto a la sujeción al Derecho Público. Por último determinar las materias en que se aplica el Derecho Privado.

\section{III.1. Patrimonio}

El artículo 10.7 del Estatuto de Autonomía de Euskadi señala la competencia de la CAPV para regular sus bienes de dominio público y patrimoniales, especificando el artículo 43.3 del mismo Estatuto que una Ley del Parlamento Vasco establecerá la administración, defensa y conservación del Patrimonio de Euskadi. A este mandato responde la Ley de patrimonio de Euskadi, en la que se establecen los principios a que debe atenerse la gestión de la CAPV en materia patrimonial. La Ley 14/1983, de 27 de Julio de 1983, de «Patrimonio de Euskadi» (BOPV n. ${ }^{\circ} 117$ de 6 de agosto de 1983) es la norma que regula la materia del patrimonio de Euskadi y, por ende, de los Entes públicos de Derecho Privado (en adelante LPE $)^{13}$. Las características principales de la Ley son:

1. Se parte de una concepción unitaria del Patrimonio.

2. Con una titularidad única, en la Administración de la Comunidad Autónoma de Euskadi.

tión en el caso Catalán. Afirma que el art. 4 de la Ley de Ordenación Sanitaria de Cataluña, según la redacción dada por la Ley 1/95, de 29 de septiembre, conforme al cual, la regla general de funcionamiento del Ente Público, Servicio Catalán de la Salud, es el Derecho Privado. No obstante, el legislador precisa que se somete al Derecho Público en: las relaciones del ente público con el Departamento de Sanidad, el régimen patrimonial, el régimen financiero, presupuestario y contable, el régimen de impugnación de sus actos y de responsabilidad patrimonial, y uno especialmente relevante, las relaciones de los titulares del derecho a la asistencia sanitaria pública con el Servicio Catalán de la Salud. La tensión subsiste en materia de contratación. Se somete a la ley de Contratos de las Administraciones Públicas, pero se remite a unas normas específicas para los conciertos sanitarios -contenidas en el Decreto 169/96, de 23 de mayo-. servicios. Lo singular de estas normas -a los efectos de este trabajo- es el cambio que se introduce en materia presupuestaria, económica y financiero al admitir, a partir de la separación de funciones de regulación, financiación y provisión, que los centros sanitarios que lo soliciten cuenten con una suerte de caja descentralizada (tesorería propia y facturación por servicios a terceros y al Departamento de Sanidad).

${ }^{13}$ La estructura de la ley consta de una exposición de motivos y tres capítulos, dedicados, respectivamente, a las disposiciones comunes sobre los bienes de dominio público y de dominio privado, al régimen de los bienes de dominio privado, y a los de dominio público. A estos capítulos, que forman el cuerpo de la Ley, se añaden cuatro Disposiciones Adicionales, una Disposición Transitoria y una Disposición Final. 
3. Abarca tanto los bienes de dominio público como los de dominio privado, superando así la dualidad tradicional en la doctrina y en la legislación positiva, y unificando también a estos efectos la llamada Administración Directa y la Administración Institucional.

En este sentido, el art. 21.3 de la LOSE establece que,

«El EPDP Osakidetza-Servicio Vasco de Salud «se sujetará al Derecho público, agotando, en su caso, sus actos la vía administrativa, cuando ejerza potestades administrativas por atribución directa o delegación, así como en cuanto a su régimen de patrimonio y en materia de responsabilidad patrimonial ante terceros por el funcionamiento de sus servicios».

Igualmente, el art. 24.2 de la LOSE establece que,

"Se adscribirán al ente público Osakidetza-Servicio Vasco de Salud los bienes y derechos propiedad de la Comunidad Autónoma de Euskadi para el cumplimiento de la finalidad que tiene encomendada. Ello se entenderá sin perjuicio de la adscripción del patrimonio de la Seguridad Social referido en las regulaciones correspondientes sobre traspaso de funciones y servicios a la Comunidad Autónoma de Euskadi ${ }^{14}$.

Ya se ha dicho que la LPE parte de una concepción unitaria del Patrimonio, con una titularidad única depositada en la CAPV y que abarca tanto los bienes de dominio público como los de dominio privado. Toma en consideración todos los bienes y derechos en posesión de los EPDP, aunque los adquieran con sus propios medios para su devolución al tráfico jurídico o para garantizar las reservas a que vengan obligados legalmente, sea cual fuere su régimen de actividad (art. 2.2 $2^{\circ}$ de la LPE). Al EPDP Osakidetza/SVS le corresponde las facultades de administración y gestión sobre los bienes y derechos que tenga adscritos ya que los titulares son bien la CAPV, como se ha dicho, bien la Tesorería General de la Seguridad Social, en virtud del Decreto de transferencia.

En relación a los inmuebles transferidos en virtud del traspaso a la CAPV de la funciones y servicios del INSALUD y de las funciones y servicios de la Seguridad Social en materia de asistencia sanitarias encomendada al Instituto Social de la Marina (ISM) se señala expresamente que se traspasan a la CAPV los bienes inmuebles y derechos que se rela-

${ }^{14}$ El art. 18 de la Ley 10/1983, de 19de mayo, de SVS/Osakidetza establecía que se afectarán al Servicio Vasco de Salud-OSAKIDETZA, de acuerdo con la Ley de Patrimonio del País Vasco: a) Los bienes y derechos de toda índole afectos a los Servicios de Salud y Asistencia Sanitaria, cuya titularidad corresponde a la Administración de la Comunidad Autónoma. b) Los bienes y derechos de toda índole afectos a los Servicios del Sistema de la Seguridad Social en los términos que se establezcan en el correspondiente Decreto de Transferencias. No hay grandes diferencias en la regulación del patrimonio bajo el régimen de Organismo Autónoma y el de EPDP. 
cionan en le inventario «con todo lo que en ellos se halle sin ningún tipo de excepción. La Comunidad Autónoma asume todas las facultades y derechos que puedan recaer sobre dichos bienes inmuebles, excepto su titularidad que continuará a nombre de la Tesorería General de la seguridad Social». Respecto a estas cuestiones nos remitimos a lo que hemos señalado al analizar los límites que impone el derecho público en la personificación de figuras de gestión privada en el ámbito sanitario.

Por su parte el art. 17 de los Estatutos Sociales del EPDP Osakidet$\mathrm{za} / \mathrm{SVS}$ establecen que de conformidad con lo dispuesto en la LPE, corresponde al Ente Público Osakidetza-Servicio Vasco de Salud, a través de sus organizaciones, la administración de los bienes y derechos que tengan adscritos de acuerdo con la Ley de Ordenación sanitaria de Euskadi.

La gestión de los bienes y derechos adscritos al Ente Público será objeto de seguimiento, tanto a través de la contabilidad patrimonial consolidada de todo el Ente Público como a través de la contabilidad patrimonial desagregada de cada una de sus organizaciones. Asimismo dichas organizaciones prestarán la colaboración que requiera la confección del Inventario General llevado por el órgano competente del Departamento de Hacienda y Administración Pública.

El Ente Público Osakidetza-Servicio vasco de salud ostentará la titularidad única sobre el capital de la sociedad pública «OSATEK-Tecnología Sanitaria de Euskadi, S.A.», correspondiendo el ejercicio de cuantos derechos deriven de aquélla al Consejo de Administración del Ente Público.

Respecto a las operaciones patrimoniales que suponen entrada de bienes o derechos en el patrimonio del Osakidetza-SVS entendemos que:

En primer lugar, la adquisición de inmuebles a título onerosos que requiera el EPDP Osakidetza para el cumplimiento de sus fines, se acuerda por el Consejero de Hacienda a propuesta del Consejero de Sanidad (art. 41 LPE). El EPDP esta obligado a colaborar en la confección el Inventario General de derechos y bienes de que sea titular, utilice o tenga adscritos (art. 11.3 LPE).

En segundo lugar, la aceptación de cesiones gratuitas de bienes a favor del EPDP Osakidetza/SVS se efectúa por el Consejero de Sanidad y en caso de que dicha cesión lleve aparejada alguna condición de uso específico debe ser aprobada por le Gobierno, a propuesta del Consejero de Sanidad y el de Hacienda (art. 63 LPE). 
En tercer lugar, los arrendamientos de bienes inmuebles a favor de EPD Osakidetza se acuerdan por el Departamento de Hacienda, a iniciativa del Consejero de Sanidad (art. 43.1 LPE).

En cuarto lugar, la adquisición de bienes y derechos por herencia o legado requiere la aprobación por decreto del gobierno, a propuesta del Consejero de Hacienda. La atribución de los bienes y derechos se hace por el Gobierno al Patrimonio de la CAPV, aunque el disponente hubiera señalado como beneficiario a EPDP Osakidetza/SVS, sin perjuicio de que en su adscripción se tenga en cuenta esa voluntad (art. 39 LPE).

En quinto lugar, la adquisición de bienes por prescripción requiere acto expreso y efectuarse expresamente su afectación (art. 54 LPE).

En sexto lugar, la adquisición de bienes muebles corporales a título onerosos se debe acordar por los representantes legales del EPDP Osakidetza/SVS, salvo cuando sea calificado como suministro, bienes homologados o vehículos automóviles y bienes informáticos (art. 42.1 LPE).

En séptimo lugar, el arrendamiento de bienes muebles se deben acordar por los representantes legales del EPDP Osakidetza/SVS con las mismas excepciones que las señaladas anteriormente (art. 43.2 LPE).

En octavo lugar, la creación e sociedades y adquisición de participaciones requiere autorización del Gobierno mediante Decreto a propuesta conjunta del Consejero de Hacienda y Sanidad. La titularidad de los derechos sobre el capital de esas sociedades pertenece al EPDP Osakidetza/SVS como ocurre con la sociedad pública OSATEK SA.

Por último, las propiedades incorporales se requiera autorización del Consejero de Hacienda (art. 45 LPE).

Respecto a las operaciones de salida de patrimonio entendemos que únicamente pueden ser enajenados por EPDP Osakidetza/SVS los siguientes bienes: los adquiridos para su devolución al tráfico jurídico en el ejercicio de sus funciones privativas; los adquiridos para garantizar la rentabilidad de las reservas que hallan de constituir en le cumplimiento e las disposiciones por las que se rijan y los bienes muebles corporales cuyo valor unitario se inferior a 25 mil pesetas.

En este sentido, el art. 241.c) de la LOSE establece que constituyen recursos del ente público Osakidetza-Servicio Vasco de Salud y de las organizaciones dependientes del mismo: «Los productos y rentas del patrimonio adscrito al mismo, perteneciente o integrante de los dere- 
chos reconocidos en el patrimonio de la Comunidad Autónoma de Euskadi».

Por último, respecto al aseguramiento del patrimonio corresponde al Departamento de Hacienda en materia de gestión de riesgos y seguros, las competencias que derivan del Decreto 356/1985, de 22 de octubre, sobre análisis, valoración, gestión, garantías de los riesgos que afectan al Patrimonio de Euskadi. En este sentido le corresponde la realización y puesta en práctica de los estudios o planes dirigidos a su prevención, control, gestión, supervisión, minoración, retención, traslación o cobertura externa; su garantía mediante la aplicación de la técnica actuarial o la contratación de Pólizas de Seguro Privado.

\section{III.2. El régimen presupuestario}

El régimen presupuestario de la CAPV se encuentra regulado en el Decreto Legislativo 1/1994, de 27 de septiembre, por el que se aprueba el Texto Refundido de las disposiciones legales sobre el Régimen Presupuestario de Euskadi, en adelante LRPE ${ }^{15}$.

De acuerdo con lo dispuesto en la LOSE, resultarán aplicables al Ente Público Osakidetza-Servicio Vasco de Salud las normas correspondientes a los Entes Públicos de Derecho Privado, de acuerdo con la legislación de la Comunidad Autónoma en las materias propias de la Hacienda General del País Vasco. Analicemos estas normas aplicables a Osakidetza ${ }^{16}$.

\footnotetext{
15 Publicado en el BOPV n. ${ }^{\circ} 44$ de 3 de marzo de 1995. Constituida por 134 artículos divididos en: una Exposición de Motivos. Título I ( Disposiciones Generales).Título II ( Contenido de los Presupuestos) que consta de dos capítulos (De los ingresos y de los gastos, los estados de los gastos). Título III (La estructura de los Presupuestos) que consta de seis capítulos (Normas generales, estructura contable, clasificación por programas, clasificación orgánica y funcional, presupuestos y estados financieros previsionales y territorialización ). Título IV (Procedimiento de elaboración de los presupuestos generales).Título $\mathrm{V}$ (El régimen de modificaciones de los presupuestos generales) que consta de nueve capítulos (Normas generales, el régimen de transferencias de créditos, variación en el nivel de competencias y servicios, habilitación de créditos, incorporación de créditos, reposición de créditos, créditos adicionales, modificaciones en los presupuestos de los Organismos Autónomos Mercantiles, Entes Públicos de derecho privado y Sociedades públicas y medidas coyunturales). Título VI (El régimen de convenios).Titulo VII (La ejecución de los presupuestos) que consta de dos capítulo (ejecución del ingresos y ejecución del gasto). Título VIII (La liquidación de los Presupuestos) y Título IX (El régimen de Prórroga). A estos Títulos hay que añadir tres disposiciones adicionales.

${ }^{16}$ En materia presupuestaria le son de aplicación los siguientes preceptos, del Decreto Legislativo 1/1994, de 27 de Septiembre, por el que se aprueba el Texto Refundido de las disposiciones legales sobre el Régimen Presupuestario de Euskadi: 8.2, 13.2 , 15, 21, 22.b, 35, 39, 51, 52, 53, 54, 55, 56, $59,97,98,124$ E y $2,128,129$, D.A. $2^{\circ}$ y los artículos $21,35,51$ de la Ley $8 / 1996$ de 8 de Noviembre, de Finanzas de la Comunidad Autónoma de Euskadi.
} 
La LOSE dispone que las organizaciones de servicios, sea cual fuere su organización jurídica, tendrán aprobados, en el marco consolidado del Ente Público, su Presupuesto Individualizado y sus Planes de Gestión a corto y medio plazo.

Por tanto, a la regulación general de la materia de régimen presupuestario propia de la Hacienda General del País Vasco a que debe sujetarse el Ente, la LOSE ha dispuesto, además, la aprobación, en el marco consolidado del Ente, su presupuesto individualizado de cada organización sanitaria o Centro Sanitario.

Tal y como se desprende de la LOSE el Ente tiene un carácter unitario a efectos de responsabilidad económica externa. Las responsabilidades presupuestarias de las organizaciones sanitarias estarán en íntima relación con el régimen de personalidad jurídica adoptada.

Características presupuestarias:

1.- Los Presupuestos del EPDP Osakidetza/SVS forman parte y se integran en los Presupuestos Generales de Euskadi conforme a lo dispuesto en el art. 2.2 de la LRPE. La características específicas en materia presupuestaria que presenta todo EPDP en al CAPV se encuentran fundamentalmente, en el art. 8.2 e la LRPE, que establece que los Presupuestos de los EPDP deben contener las dotaciones de gastos y de ingresos, de inversiones y financiación el ejercicio así como de compromisos futuros.

2.- Los créditos de pago para gastos de personal recogidos en los estados de gasto de los presupuestos del E.P. Osakidetza tendrá carácter limitativo en lo relativo a la cuantía del crédito.

3.- La estructura del Presupuesto del EPDP Osakidetza/SVS se establece por el Departamento de Hacienda y Administración Pública conforme al art. 35.1 de la LRPE. Lo único que puede hacer Osakidetza es desarrollar dicha estructura presupuestaria conforme a sus peculiaridades. Más específicamente, el Capítulo V del título III de la LRPE dedicado a la estructura presupuestaria (arts. 51 a 56) y con el fin de integrarse en los Presupuestos Generales de la Comunidad Autónoma de Euskadi deben elaborase.

Los presupuestos de explotación y de capital siguiendo las normas que se establecen así como el estado de los compromisos futuros. A su vez deben acompañarse los estados financieros pervisionales correspondientes al balance previsional al cierre del ejercicio presupuestario, la cuenta de pérdidas y ganancias previsional y un cuadro de financiación previsio- 
nal, elaborado conforme al Plan General de Contabilidad. A ello se une una Memoria comprensiva de sus actividades generales como la clasificación territorial de los gastos de personal a realizar durante el ejercicio.

4.- No obstante, se habilita un procedimiento en virtud del cual la limitación del importe de consignado en los presupuestos del Ente permita disponer de un importe superior al inicialmente consignado. Este procedimiento es el de la modificación presupuestaria.

Respecto a las modificaciones presupuestarias que quiera efectuar el EPDP Osakidetza/SVS estarán sujetas a las normas contenidas en el Capítulo VII del título V de la LRPE. Se establece en los arts. 97 a 99 un régimen específico para los EPDP. Es muy importante la sujeción que hace la norma al respecto ya que se entiende por modificación presupuestaria en los presupuestos de explotación o de capital de los Entes Públicos toda variación en los importes de los conceptos considerados limitativos que son:

a) Inversiones en inmovilizado material o inmaterial.

b) Inversiones financieras.

c) Gastos de Personal.

d) Transferencias y subvenciones corrientes y de capital concedidas.

e) Recursos ajenos.

Las modificaciones presupuestarias deben ser autorizadas por el Departamento de Hacienda salvo que supongan una modificación en los objetivos del EPDP Osakidetza/SVS, en cuyo caso corresponde al Gobierno a propuesta del Departamento citado. De igual manera, se está a la autorización del departamento de Hacienda en el supuesto que se pretenda incrementar el estado de compromisos futuros, o en su caso el Consejo de Gobierno previa aprobación de la Comisión delegada de asuntos Económicos según el porcentaje de incremento respecto a los inicialmente autorizados.

5.- En el supuesto de que la Ley de Presupuestos Generales de un ejercicio extendiese su vigencia al siguiente con carácter de prorroga, las autorizaciones contenidas en los presupuestos Generales del ejercicio precedente se entenderán prorrogados. En el caso de los gastos de personal del Ente Osakidetza, se entiende que se podrán proceder a la cobertura de la plantilla hasta completar el límite aprobado en los presupuestos objeto de prórroga. Del mismo modo, el Gobierno puede incrementar las retribuciones de personal del Ente en un porcentaje máximo y provisional, aplicado individualmente, idéntico al autorizado en la última Ley de Pre- 
supuestos Generales. En caso de asunción de nuevas competencias y/o servicios por parte del Ente, en periodo de prórroga, el Gobierno autorizará la consignación de créditos de pago para atender exclusivamente los gastos de personal y generales, limitados a los medios materiales y humanos objeto de transferencia, ampliados en los medios mínimos necesarios para el desarrollo de las competencias y/o servicios durante el período de prórroga.

8.- La dotación de las transferencias y subvenciones que figuren en los presupuestos de la Administración General de la Comunidad Autónoma en favor del Ente Público Osakidetza, se harán efectivas siguiendo unas normas según se trate de dotaciones para gastos corrientes y los previstos por períodos anticipados y en importes proporcionales a dichos períodos y a la dotación total, incluidas las modificaciones presupuestarias aprobadas hasta ese momento. Las segundas, se harán efectivas en el momento en que surja la necesidad de acometer pagos de la referida naturaleza.

En los Presupuestos Generales de la CAPV pueden consignarse transferencias tanto corrientes y de capital a Osakidetza que debe figurar en la sección presupuestaria del departamento de sanidad y tienen para Osakidetza el carácter presupuestario que establece el art. 15 de la LRPE, esto es:

a) Las transferencias y subvenciones corrientes forman parte de los estados de ingresos de Osakidetza.

b) Las transferencias y subvenciones de capital constituyen para Osakidetza los recursos destinados a la financiación de operaciones de capital, sin reflejo en el resultado de sus actividades, salvo que la finalidad de las transferencias lo hayan sido para conceder a su vez subvenciones y transferencias de capital a tras prosas o Entes.

Por último, el art. 21 de la LRPE prevé que los créditos de pago correspondientes a las transferencias corrientes tienen para los perceptores la naturaleza de subvención en la medida necesaria para equilibrar su cuenta de pérdidas y ganancias por lo que en caso d existencia d excedentes, los mismo se integrarán en la Tesorería General del País Vasco.

Una vez señaladas las normas generales aplicables a Osakidetza en materia presupuestaria contenidas en la LRPE veamos las especialidades recogidas en la LOSE y en los Estatutos Sociales del Ente que completan aquella Ley.

De acuerdo con lo dispuesto en el artículo 24.1.a) de la Ley de Ordenación Sanitaria de Euskadi, la dotación inicial con la que se constituye el Ente Público Osakidetza-Servicio vasco de salud será la que al efecto 
figure en los Presupuestos Generales de la Comunidad Autónoma de Euskadi para el ejercicio de 1998, sin perjuicio de la valoración definitiva que corresponda a los activos que le sean adscritos al Ente Público al inicio de sus actividades.

Los recursos del Osakidetza de los ejercicios posteriores estarán constituidos por:

a) Los créditos que con destino al mismo consignen los Presupuestos Generales de la Comunidad Autónoma de Euskadi.

b) Los productos y rentas del patrimonio adscrito al mismo, perteneciente o integrante de los derechos reconocidos en el patrimonio de la Comunidad Autónoma de Euskadi.

c) Los ingresos de Derecho privado generados por el ejercicio de su actividad o por la prestación de servicios a terceros, cuando concurran obligados al pago de los mismos.

d) Cualquier otro recurso que legalmente le pueda ser atribuido.

La aplicación de las normas de la LRPE, se tendrán en cuenta las siguientes circunstancias a tenor del art. 18 de los Estatutos Sociales:

a) Cada organización dispondrá de un Presupuesto de explotación y de capital; un estado de compromisos futuros, en su caso; una Memoria anual comprensiva de sus actividades, principales realizaciones y objetivos a alcanzar cuantificados; así como la información adicional de sus Estados financieros previsionales, que comprenderán Balance Previsional al cierre del ejercicio, Cuenta de Pérdidas y Ganancias Previsional y Cuadro de Financiación Previsional.

b) Por el Consejo de Administración del Ente Público se establecerán los procedimientos de elaboración y liquidación de los Presupuestos en el ámbito de las organizaciones del Ente, teniendo en cuenta su adecuación con los procedimientos establecidos para la elaboración y liquidación de los Presupuestos Generales de la Comunidad Autónoma.

c) Las dotaciones, tanto del presupuesto de explotación como del presupuesto de capital de cada una de las organizaciones del Ente Público, tendrán carácter estimativo en todo caso, sin perjuicio de que en el ámbito consolidado de todo el Ente Público tengan carácter limitativo, conforme dispone la legislación aplicable. La organización central del Ente Público informará los presupuestos de las organizaciones de servicios sanitarios, señalando los límites de gasto que permiten la consolidación en todo el Ente Públi- 
co y sujetando a autorización por parte de la organización central toda variación del importe en los conceptos que son considerados limitativos para el conjunto del Ente Público por encima de los límites establecidos. Asimismo el informe deberá rechazar aquellas previsiones por cualquier concepto que resulten contrarias al marco estratégico que tenga aprobado cada organización de servicios.

d) Al objeto de posibilitar una mayor eficiencia e integración del conjunto de organizaciones dependientes del Ente Público Osakidetza-Servicio vasco de salud, se podrá establecer un «Fondo Central de Compensación» mediante aportaciones fijadas en función de las características y presupuesto de cada organización de servicios, agotándose, en su caso, con carácter previo a la formulación definitiva de la cuenta de Pérdidas y Ganancias del Ente Público.

En definitiva, el régimen presupuestario que regula la actividad presupuestaria del Ente está recogida en las normas de derecho público que rigen a la Administración pública Vasca y en sus normas de desarrollo. Estas normas no otorgan ninguna autonomía a Osakidetza ya que toda su actividad presupuestaria se encuentra tutelada por las competencias que el ordenamiento jurídico le otorga, fundamentalmente, al Consejo de Gobierno y al Departamento de Hacienda, así como al Departamento de Sanidad en cuanto que se constituye como un Ente instrumental dependiente de dicho Departamento.

\section{III.3. El control del presupuesto}

Las tareas de control de la ejecución presupuestaria del gasto público se han divido tradicionalmente en el denominado control interno o administrativo y control externo. No nos referiremos, por tanto al control jurisdiccional, ni al control político derivado de la actividad parlamentaria, sin perjuicio de hacer referencia al control del Tribunal Vasco de Cuentas Públicas.

\section{A) El control interno interventor}

El control ceconómico-financiero y de gestión de carácter permanente al que se sujeta la actividad económica de Osakidetza es la modalidad de control interventor que se encuentra regulada en el capítulo III, arts. 17 a 20 de la Ley 14/1994, de 30 de junio, de Control y Contabilidad de la 
Comunidad Autónoma de Euskadi (BOPV n. ${ }^{\circ}$ 145, de 1 de agosto), en adelante LCEC y el capítulo III, sección primera, arts. 10 a 23 del Decreto $464 / 1995$, de 31 de octubre, citado $^{17}$.

Por la importancia cuantitativa y especialidad cualitativa que supone el gasto sanitario, haremos referencia al art. 21.2 de la Ley 8/1997, de 26 de junio, de Ordenación sanitaria de Euskadi y la Disposición Adicional Tercera del Decreto 255/1997, de 11 de noviembre, por el que se establecen los Estatutos Sociales del Ente Público Osakidetza- Servicio Vasco de Salud. Estas últimas normas contemplan, por primera vez, una modalidad de control específico que se integra en el nomem general de control económico-financiero y de gestión pero que presenta unas importantes características diferenciales. Se trata de la modalidad de control económicofinanciero y de gestión de carácter permanente más ajustado a las necesidades de algunos entes del Sector Público de la CAPV. Dicho esto pasemos a ver la regulación jurídica de este control interventor así como a determinar sus características ${ }^{18}$.

Teniendo en cuenta lo anterior, la LCEC señala en su art. 18.2 que en relación al momento de efectuar el control, se establecen dos posibles momentos:

El primero, de carácter general, que se corresponde con la mayoría de los supuestos de control, es el que se realiza en un momento posterior a la conclusión de un ciclo temporal y/o económicamente trascendente para el sujeto a ser controlado según su naturaleza.

El segundo, de carácter especial y restringido como lo demuestra su escasa implantación, es aquel que, cuando así se determine, el control económico-financiero y de gestión se puede realizar de modo permanente incluso en servicios o unidades administrativas.

Vamos a detenernos en el análisis de esta segunda modalidad por lo que supone de especialidad respecto a los controles financieros habituales. Concretamente la Administración de la CAPV ha establecido reciente-

\footnotetext{
${ }^{17}$ El control interventor de carácter financiero y de gestión sale fortalecido en el modelo propuesto al ser aquel que más sinceramente cumple con la universalidad del objeto que se predica en los principios rectores del control público. Se potencia este control e incluso se le dota de cierto carácter de reposición contable al establecer la posibilidad de dictar actas de control con fuerza para exigir responsabilidades. Por lo demás, es un control auditor típico a todos los niveles que debe servir para medir la eficacia, eficiencia y economía de la Administración pública vasca.

${ }_{18}$ Me remito a mi artículo «Características Jurídicas del control financiero de las Administraciones Vascas: especialidad del control del gasto sanitario» en la Revista Jurídica La Ley, no 4906, AÑO XX. Sección doctrina. Madrid, 1999.
} 
mente, por primera vez en el Sector Público Vasco, esta modalidad de control para el ámbito sanitario ${ }^{19}$.

\section{Ambito de aplicación}

El control financiero permanente se puede establecer sobre los Departamentos, Organismos, Servicios, Sociedades y entes Públicos cuyo volumen presupuestarios, actividades económicas, o modelo de gestión así lo aconsejen, en los términos y con el alcance que determine el Consejero de Hacienda y Administración Pública.

Se caracteriza este control por que las actuaciones y trabajos necesarios para su desarrollo se efectúan de forma permanente y continuada a lo largo de los diferentes ejercicios y por que las actuaciones se deben realizar, como regla general, sobre la base del principio de proximidad temporal respectos de la actividad o los actos objeto de control, tal como regula el art. 12 del Decreto 464/95. Para este trabajo la Oficina de Control Económico debe recibir del ente sujeto a control la información actualizada y detallada de la actividad objeto de control, en la forma y periodicidad que la propia Oficina determine, a fin de tener un conocimiento completo de la misma.

La única decisión que se ha tomado para la implantación de este novedoso sistema de control ha correspondido al ámbito sanitario de la CAPV. En concreto el art. 21.2 a) de la Ley 8/1997, de 26 de junio, de Ordenación sanitaria de Euskadi establece que el control económico del Ente Público de Derecho Privado Osakidetza/Servicio Vasco de Salud, que se crea por la referida Ley, « se ejercitará en la modalidad de control económico-financiero y de gestión de carácter permanente, de acuerdo con los establecido en la Ley 14/1994, de 30 de junio, de Control económico y contabilidad de la Comunidad Autónoma de Euskadi».

\footnotetext{
19 Sobre el control de los gastos sanitarios de la CAPV me remito a mis siguientes trabajos anteriores: J.A. ARRATIBEL ARRONDO, «Euskal osasun-sistemaren finantzaketa, aurrekontua eta kontrol ekonomikoaren azterketa: osasun antolamenduari buruzko 8/1997 Legearen irakurketa» en Revista Vasca de Administración Pública n. ${ }^{\circ}$ 52, setiembre-diciembre 1998, pp. 33 a 78; « Euskadiko Osasun Antolamenduari buruzko 8/1997 Legea: osasun gastua eta Ongizate estatuaren egonkortasuna» en Revista Jurídica de las Sociedad de estudios Vascos «ELERIA» n. ${ }^{\circ}$ 3, 1998, pp. 5 a 22. «Características Jurídicas del control financiero de las Administracions Vascas: especialidad del control del gasto sanitario» en la Revista Jurídica La Ley, n. ${ }^{\circ}$ 4906, AÑO XX. Sección doctrina. Madrid.1999. «El control financiero y de gestión del gasto sanitario en Euskadi» en Revista Auditoria Pública n. ${ }^{\circ}$ 19 (Diciembre 1999). Ed. Revista de los Organos Autonómicos de Control Externo. Pamplona, 1999, pp. 33-41.
} 
En este sentido, la Disposición Adicional Tercera del Decreto 255/97, de 11 de noviembre, por el que se establecen los Estatutos Sociales del Ente Público Osakidetza-Servicio Vasco de Salud complementa la anterior norma al señalar que el control financiero permanente sobre la actividad sanitaria se llevará a cabo de conformidad con lo dispuesto en el art. 12 del Decreto 464/95. El Decreto 255/97, de 11 de noviembre (BOPV n. ${ }^{\circ} 219$, de 14 de noviembre de 1997) establece que el control económico financiero de gestión de carácter permanente se ejercerá por la Intervención en Osakidetza, la cual realiza sus funciones en nombre y por delegación del Director de la Oficina de Control Económico. Esta Intervención en Osakidetza tiene nivel orgánico de Dirección estando adscrita orgánicamente a la Dirección General del Ente Público y funcionalmente ala Oficina de Control Económico, y su titular, llamado Interventor en Osakidetza, es nombrado por le Gobierno a propuesta del Consejero de Hacienda y Administraciones Públicas. La persona requerida para ejercer las funciones de control financiero permanente pertenece a la estructura y plantilla de la Oficina de Control Económico y se encuentra presupuestado en los programas correspondientes de la Oficina de Control Económico.

La importancia de esta modalidad de control económico es doble: por un lado, la novedosa regulación jurídica de la misma; por otro, la importancia cuantitativa sobre el ámbito que se ejerce el control que representa el 31,7\% de presupuesto de gastos de la Administración de la CAPV ${ }^{20}$.

\section{Características del control en el ámbito de Osakidetza}

Las bases normativas sobre las que se sustenta sus especialidad se encuentran a nuestro juicio en las siguientes:

En primer lugar, se realiza en un momento posterior a la conclusión de un ciclo temporal y/o económicamente trascendente para el sujeto a ser controlado, según su naturaleza. No obstante, cuando así se determine, el control económico-financiero y de gestión puede realizarse de modo permanente incluso en servicios o unidades administrativas (art. 18.2 de la LCEC).

\footnotetext{
20 Las dotaciones presupuestarias para el ejercicio 1998 ascienden a 233.608,2 millones de pesetas. El Departamento de Sanidad tiene a su cargo el presupuesto citado divido en tres programas a saber: Administración General: Estructura y Apoyo (2.596), Aseguramiento y Contratación (228.050 ) y Salud Pública $(2.961,4)$.
} 
En segundo lugar, hemos dicho que se puede establecer esta modalidad de control en los Departamento, Organismos, Servicios, Sociedades y Entes Públicos cuyo volumen presupuestario, actividades económicas o modelo de gestión, así lo aconseje, en los términos y alcance que se determine por el Consejero de Hacienda y Administración Pública. Pero este control se ha de ejecutar de forma permanente y continuada a lo largo de los diferentes ejercicios, sobre la base del principio de proximidad temporal respecto de la actividad o los trabajos objeto de control. Para ello, la Oficina de Control ha de recibir información actualizada y detallada de la actividad objeto de control en la forma y con la periodicidad que dicha Oficina determine, a fin de tener un conocimiento completo de la misma (art. 12 del Decreto 464/1995).

\section{Plan de actuaciones}

Este control se materializa en un Plan de actuaciones, en el que se determina la clase y el alcance de los controles a realizar y es aprobado por el Consejero de Hacienda mediante la correspondiente Orden. Hasta la fecha únicamente se han aprobado mediante Orden dos Planes de actuación de control financiero permanente y de gestión.

La primera Orden del Consejero de Hacienda ha sido la dictada el 30 de junio de 1998, por la que se establece el Plan de Actuaciones de Control Financiero Permanente para 1998, a realizar por la Intervención en Osakidetza sobre los actos de contenido económico del Ente público de Derecho Privado Osakidetza/Servicio Vasco de Salud.

La segunda Orden ha sido la de 1 de febrero de 1999, de la Consejera de Hacienda, por la que se establece el Plan de Actuaciones de Control Financiero Permanente para 1999, a realizar por la Intervención en Osakidetza sobre los actos de contenido económico del Ente público de Derecho Privado Osakidetza/Servicio Vasco de Salud.

\section{El módulo informatizado de control}

La información para el ejercicio del control se instrumentaliza, fundamentalmente, a través de un módulo de control económico-financiero soportado mediante un sistema informático diseñado para tal fin.

Este sistema informático es el denominado SAP-R-3. El Gobierno Vasco ha adquirido este sistema informático para su aplicación en la ges- 
tión de la sanidad. Cuenta con tres módulos iniciales: el primero abarca la contratación, gestión de inventario y stock-almacenes; el segundo la gestión de inventarios, control de gestión y facturación y el tercero las distintas cuentas a pagar, a cobrar, la contabilidad patrimonial, la tesorería y la gestión de activos, al que se le ha añadido un cuarto módulo relativo al control económico-financiero y de gestión de carácter permanente.

Este último módulo es el utilizado por la Intervención para dar contenido a la labor de control financiero permanente. El módulo es un instrumento para los trabajos de control fundamentalmente en tres aspectos:

Por una lado, permite el análisis de la actividad económica del Ente Público Osakidetza.

En segundo lugar, los informes que presenta el módulo contienen información sobre determinados aspectos susceptibles de determinar los criterios de muestreo (cuantías, períodos, proveedores, etc.) y ordenar esa información de acuerdo con tales criterios.

Por último, relaciona la información sobre la actividad económica con su reflejo contable.

\section{Emisión de informes}

La emisión de los informes siguen un procedimiento y estructura concretos que posibilitan la audiencia del Ente sometido a control económico-financiero y de gestión de carácter permanente.

De conformidad con las instrucciones que se han dictado hasta la fecha por el Interventor en Osakidetza, una vez definidas las actuaciones de control y la metodología del trabajo, éste culmina con la emisión del correspondiente informe provisional.

Estos informes se remiten por el órgano que hubiera efectuado el control al titular de la organización de servicios controlada, acompañados de un escrito de remisión en el que se indica un plazo de quince días para que se efectúen las alegaciones que éste considere oportunas.

Sobre la base del informe provisional y de las alegaciones recibidas, el órgano de control emite informe definitivo que incluirán las alegaciones recibidas y, en su caso, las observaciones del órgano de control sobre las mismas. 
Por lo que se refiere a la estructura y contenido de los informes hay que decir que siguen un esquema general que contiene la siguiente información:

- Una introducción en al que se indica la competencia para realizar el control y el órgano que emite el informe;

- unas consideraciones generales sobre la estructura organizativa del Ente sujeto a control; definición de los objetivos genéricos y particulares y alcance del control y sus limitaciones si las hubiera;

- los resultados del control en los que se recogen la evidencia y los hechos constatados como consecuencia de las pruebas realizadas en relación a los objetivos del control.

- por último, las consideraciones generales relativas a los aspectos más significativos de los resultados obtenidos con expresa opinión del órgano de control así como las conclusiones relativas al cumplimiento de legalidad o a la gestión, así como las recomendaciones para corregir las debilidades y defectos puestos de manifiesto.

\section{B) El control del TVCP}

Pero además de esta control interno ejercicio por le Departamento de Hacienda, mediante la Intervención en Osakidetza, existe un control externo, ejercido por el Tribunal Vasco de Cuentas Públicas en virtud de Ley $1 / 1988$, de 5 de febrero (LTVCP). Respecto al ámbito y extensión del control se encuentran el art. $2^{\circ}$ a) de la LTVCP. Así se dispone que sin perjuicio de las competencias atribuidas al Tribunal de Cuentas del Estado, el Tribunal Vasco de Cuentas Públicas extiende su control a la actividad del Sector Público Vasco que a los efectos de esta LTVCP está integrado, entre otros, por los entes públicos de Derecho Privado ${ }^{21}$.

\footnotetext{
${ }^{21}$ Este artículo dispone que el Tribunal Vasco de Cuentas Públicas extiende su control a la actividad del Sector Público Vasco que a los efectos de esta LTVCP está integrado por: La Administración General o Administración de la Comunidad Autónoma de Euskadi en los términos definidos por la LPOHG. La Administración Institucional integrada por: los Organismos Autónomos, Entes Públicos de Derecho Privado y Sociedades Públicas en los términos definidos en la LPOPH incluida, en su caso, la Seguridad Social. - Las Juntas Generales y las Diputaciones Forales de cada uno de los Territorios Históricos y los Entes Institucionales y Sociedades Públicas de ellos dependientes.- Las Entidades Locales y los entes Institucionales y Sociedades Públicas de ellos dependientes, en razón a las peculiaridades del régimen económico-financiero establecido en la Ley de Concierto. Cualquier otra entidad que administre o utilice caudales o efectos públicos procedentes de los entes anteriormente enumerados.
} 
Por tanto, las normas que regulan el control interno administrativo (interventor) y externo (Tribunal de Cuentas del Estado y Tribunal Vasco de Cuentas Pública) aplicables al Servicio Vasco de Salud son las generales aplicables a toda la Administración Pública Vasca contenidas en las normas de derecho público que hemos citado.

\section{III.4. Contratación}

El art. 21.2.c) de la LOSE establece que la contratación se ajustará a las previsiones que para cada personificación jurídica establezca la legislación sobre contratos de las Administraciones públicas. En este sentido, el art. 1 del Real Decreto Legislativo 2/2000, de 16 de junio, por el que se aprueba el texto refundido de la Ley de Contratos de las Administraciones Públicas dispone que en el ámbito de aplicación subjetiva de la Ley a las entidades de derecho público con personalidad jurídica propia vinculadas o dependientes de las Administraciones públicas siempre que se den los siguientes requisitos:

a) Que hayan sido creadas para satisfacer específicamente necesidades de interés general que no tengan carácter industrial o mercantil.

b) Que se trate de entidades cuya actividad esté mayoritariamente financiada por las Administraciones Públicas u otras entidades de derecho público, o bien, cuya gestión se halle sometida a un control por parte de estas últimas, o cuyos órganos de administración, de dirección o de vigilancia estén compuestos por miembros más de la mitad de los cuales sean nombrados por las Administraciones Públicas y otras entidades de derecho público.

Por tanto, Osakidetza cumple con estos requisitos y se encuentra sujeta a la Ley de Contratos de las Administraciones Públicas en todos sus extremos.

\section{A) Contratación Administrativa}

En este sentido la CAPV dictó el Decreto 136/1996, de 5 de junio, sobre régimen de contratación de la Administración de la Comunidad Autónoma de Euskadi aplicable a la Administración General y a sus Organismos Autónomos ${ }^{22}$. En principio, del ámbito de aplicación de este

22 La exposición de motivos del Decreto citado recordaba el sometimiento de los entes públicos de derecho privado a la Ley de Contratos de las Administraciones Públicas en los supuestos en esta pre- 
Decreto parece excluirse los Entes Públicos de Derecho Privado. No obstante, la Disposición Adicional Tercera establece que,

«Las disposiciones de este Decreto aplicables con carácter general a los organismos autónomos se extenderán, en cuanto a su aplicación, a los Entes Públicos de Derecho Privado en relación con las contrataciones que, conforme a la Ley de Contratos de las Administraciones Públicas, deben someterse a la citada Ley».

Por tanto, se extienden las normas de contratación del Decreto 136/1996 correspondientes a los Organismos Autónomos Administrativos al Ente Público de Derecho Privado Osakidetza-Servcio Vasco de Salud.

En este mismo sentido, el art. 20 de sus Estatutos Sociales recoge la regulación de las normas sobre régimen orgánico de contratación en el EPDP Osakidetza/SVS. La características que presenta esta regulación es la siguiente.

a) Se reafirma nuestra opinión sobre la aplicación del Real Decreto Legislativo 2/2000, de 16 de junio, por el que se aprueba el texto refundido de la Ley de Contratos de las Administraciones Públicas y el Decreto 136/1996. Este precepto dispone que el régimen general de la contratación y adquisición de bienes y servicios necesarios para el ejercicio de las funciones del Ente Público Osakidetza-Servicio vasco de salud y sus organizaciones de servicios será el establecido en la. Ley citada.

Asimismo en todo aquello que no se oponga a lo establecido en el presente artículo, las disposiciones del Decreto 136/1996, de 5 de junio, sobre régimen de la Contratación de la Comunidad Autónoma de Euskadi, se extenderán en cuanto a su aplicación al Ente Público OsakidetzaServicio vasco de salud, en los términos establecidos por la citada disposición adicional tercera de dicho Decreto.

b) Son órganos de contratación en el Ente Público Osakidetza-Servicio vasco de salud el Director General o el Director-Gerente, o el cargo directivo del equipo correspondiente en quien el mismo delegue, en función de cada una de las organizaciones que tenga reconocidas el Ente Público.

\footnotetext{
visto, aconseja extender el régimen establecido en este Decreto a dichos entes en relación con las contrataciones sometidas a la referida ley. Respecto a Osakidetza se establecía que en tanto no se estructure definitivamente el proyecto «Osasuna Zainduz», la aplicación del presente Decreto al organismo autónomo Servicio Vasco de Salud/Osakidetza, se realiza con las singularidades previstas en la disposición adicional segunda.
} 
En todo caso, el Director General del Ente Público, o el cargo directivo de la organización central en quien delegue, será el órgano de contratación competente en los supuestos de avocación de la competencia, para las contrataciones centralizadas y para las compras de suministros que le correspondan de entre las consideradas integradas, todo ello de acuerdo con las instrucciones que al respecto establezca el Consejo de Administración del Ente Público.

c) Define los conceptos de contrataciones centralizadas y compras de suministros integradas.

Se define las contrataciones centralizadas como «aquellas que determine el Consejo de Administración del Ente Público en atención a su carácter estratégico, así como los procedimientos de homologación que acuerde la Dirección General del Ente Público».

Son consideradas compras de suministros integradas aquellas que, «estando sujetas a cualquiera de las condiciones anteriormente expuestas para la contratación centralizada, se apliquen en todas las organizaciones del Ente Público y se sometan a una planificación específica con participación activa de los destinatarios de los suministros».

La importancia de la definición conceptual y su propia diferenciación estriba, en nuestra opinión, en los siguiente:

En primer lugar, resuelve algunos de los problemas tradicionales sobre la centralización de la contratación administrativa en un ente con un gran poder de compra y diversos órganos de contratación.

En segundo lugar, evita tensiones entre los distintos órganos de contratación al determinar exactamente cuales son contrataciones centralizadas y cuales compras de suministros integradas.

En tercer lugar, evita que las compras, sobre todo los suministros, sean homogéneos en toda la red pública vasca.

Por último, el volumen de compra tiene una incidencia directa en el precio de los suministros adquiridos. Supone, indirectamente, un sistema de control de los gastos públicos y de presión sobre los precios de mercado.

d) La Dirección General del Ente Público, previa autorización del Consejo de Administración del mismo ha creado las Mesas de Contratación que ha considerado necesarias, en función del dimensio- 
namiento de las distintas organizaciones del Ente Público y para el ejercicio de las funciones de asistencia al órgano de contratación en la adjudicación de los contratos, conforme a las previsiones contenidas en el artículo 82 de la Ley 13/1995, de Contratos de las Administraciones Públicas.

Las Mesas de Contratación que se creen deben estar en todo caso compuestas por los siguientes miembros:

a) Presidente: un cargo directivo de la organización respectiva distinto al que sea el órgano de contratación de la misma.

b) Dos vocales designados por el órgano de contratación.

c) Un vocal-secretario designado por el órgano de contratación de entre los letrados o los técnicos de gestión licenciados en derecho adscritos a la organización correspondiente, que ejercerá las funciones de Asesor Jurídico y Secretario de la Mesa, con voz y voto.

La Mesa de Contratación puede solicitar, antes de formular su propuesta, cuantos informes técnicos considere precisos y se relacionen con el objeto del contrato.

El órgano de contratación correspondiente puede apartarse de la propuesta formulada por la Mesa de Contratación mediante resolución motivada. El vocal-secretario de la Mesa de Contratación tiene a su cargo el seguimiento de los actos de ordenación e instrucción, así como la constancia, archivo y seguimiento de todos los actos de preparación, licitación, adjudicación, formalización, ejecución y extinción de los contratos. Asimismo informará los pliegos de cláusulas administrativas particulares y ejercerá la asesoría jurídica en cuantos incidentes se produzcan en los expedientes que la Mesa conozca en el ejercicio de sus funciones.

En definitiva, podemos concluir que, en materia de Contratación Administrativa, el Ente Público de Derecho Privado Osakidetza está sujeto a las normas generales de contratación pública contenidas en la Ley 13/1995, de Contratos de las Administraciones Públicas y en el Decreto 136/1996. Est supone, entre otras cuestiones que goza de la prerrogativas propias de la administración pública contratante fijadas en el ordenamiento jurídico (ius variandi, pliegos administrativos, suscripción en documento administrativo, interpretación, extinción, la apreciación del interés general etc.). 


\section{B) El Contrato Programa}

El contrato-programa fue utilizado de modo experimental con anterioridad al 1 de enero de 1998, esto es, ante de la publicación de la LOSE. Estos primeros contratros-programa fueron suscritos entre los centros del Servicio Vasco de Salud-Osakidetza y las Direcciones de Área del mismo Servicio Vasco de Salud. Fueron un ensayo de lo que en un futuro sería (hoy realidad) la relación entre el Departamento de Sanidad y los centros sanitarios dependientes del Ente Público de Derecho Privado Osakidetza. Hasta la referida fecha, y desde su aparición en la Ley de Presupuestos de la CAPV de 1994 fue tenido como un elemento de gestión con ciertas características que la asemejaban a un contrato donde se fijaban objetivos de salud, financiación así como pautas para la promoción de la calidad en los servicios ${ }^{23}$.

A partir de 1998, el art. 21.1b) de la LOSE establece que Osakidetza «en sus relaciones con el Departamento competente en materia de sanidad se sujetará a las disposiciones de esta ley por las que se regulan los contratos-programa».

El artículo 19 de la LOSE prevé la suscripción de contratos-programa para articular las relaciones entre el Departamento de Sanidad y las organizaciones del Ente Público Osakidetza para la provisión de servicios sanitarios. A este respecto, al mencionado contrato-programa se le configura como Convenio de carácter especial y por lo tanto está exento de la aplicación del Real Decreto Legislativo 2/2000, de 16 de junio, por el que se aprueba el texto refundido de la Ley de Contratos de las Administraciones Públicas.

En él se concretan, en relación con la actividad y financiación con cargo a los créditos presupuestarios públicos, los siguientes extremos mínimos:

- Estimación del volumen global de actividad y previsión de las contingencias sanitarias objeto de cobertura.

- Determinación cuantificable y periódica de los requisitos de calidad que deberán cumplir los servicios sanitarios.

\footnotetext{
${ }^{23}$ Sobre este particular se puede consultar la Resolución 41/1997, de 2 de junio, del Presidente del Tribunal Vasco de Cuentas Públicas, por la que se hace público el Análisis de la situación de los contratos-progrmas en el SVS-Osakidetza, publicado en le BOPV n. ${ }^{\circ} 131$, de 19 de julio de 1997. No se puede definir el documento suscrito antes de 1998 como contrato, ya que las partes intervinientes no tienen personalidad jurídica diferenciada, puesto que ambas forman parte de la organización del Organismo Autónomo Osakidetza. La actividad desarrollada en aquel momento mediante los denominados contratos-programa no es más que una forma de gestión de servicio público a través de unidades de gestión diferenciadas, sin personalidad jurídica, acorde con la actual estructura del Servicio Vasco de Salud-Osakidetza.
} 
- Estimación finalista sobre cobertura económica de la actividad consignada con cargo a los créditos presupuestarios, periodicidad de los pagos y documentación justificativa para la realización de los mismos.

- Requisitos y procedimiento de control y auditoría sanitaria.

- Los niveles de responsabilidad que adquieren las partes en cuanto a las revisiones, adaptaciones y demás incidencias que se susciten en la aplicación del convenio.

El contrato-programa se suscribe con la representación legal de la organización de provisión de servicios sanitarios, sin distinción entre aquéllas que, en futuro, tengan personalidad jurídica propia respecto de las que carezcan de la misma. Es decir, el mencionado contrato-programa sirven tanto para los centros del Ente que adopten una personalidad jurídica propia conforme al artículo 23.2 de la LOSE como para los que carezcan de la misma.

El contenido del contrato-programa gravita en torno a la actividad pactada y su precio: -La actividad se desglosa en la derivada de la hospitalización y la resultante de consultas y urgencias no ingresadas. La hospitalización puede ser genérica y por procesos singularizados (varices, cataratas, etc.) que se individualizan por su sencillez, clara identificación y por su peso económico e interés en su control, entre otras razones. Adicionalmente se pacta la realización de programas especiales. La unidad de medida de la actividad de hospitalización genérica es el punto GDR (punto de complejidad), que se obtiene de la codificación de los diagnósticos principales y secundarios del paciente, aplicada sobre el programa informático $\mathrm{CMBD}$, que es un sistema de clasificación de pacientes. En la actividad de procesos singularizados, consultas y urgencias la unidad de medida es el número de procesos o actos realizados y los programas especiales se pactan de forma global, sin un detalle individualizado. El contrato-programa señala un precio para cada una de las actividades descritas.

El contrato-programa a pesar de su carácter de Convenio especial, es un documento administrativo y por tanto le serán de aplicación las normas y principios generales del derecho administrativo, y en cuanto acto susceptible de producir obligaciones y derechos para la Administración Pública, sujeto al control económico de carácter interventor en su modalidad económico fiscal ${ }^{24}$.

\footnotetext{
24 Respecto los contratos-programas suscritos tanto por el INSALUD como por las distintas CCAA se puede consultar J.J. MARTÍN MARTíN, « Cambio e innovación institucional. Las nuevas experiencias en gestión sanitaria» en Informe SESPAS 1998: La Salud Pública y el Futuro del Estado del Bienestar. Ed. Escuela Andaluza de salud Pública, Granada, 1998, p. 428 a 448.
} 


\section{III.5. Régimen de Tesorería, Finanzas y Contabilidad}

Estas materias propias de la Hacienda General son las que con rotundidad se puede afirmar que están sometida al Derecho Privado.

Los regímenes jurídicos de Tesorería, Finanzas y Contabilidad de la CAPV se encuentran regulados en normas diversas. Estas normas se encuentran, en primer lugar, sobre todo contenidas en la Ley/1996, de 8 de noviembre, de Finanzas de la Comunidad Autónoma de Euskadi (BOPV n. ${ }^{\circ} 233$, de 3 de diciembre de 1996. En segundo lugar, también encontramos algunas normas, sobre todo de contabilidad, en la anteriormente citada Ley 14/1994, de Control Económico y Contabilidad de la $\mathrm{CAE}^{25}$.

Por tanto, en nuestra opinión, el EPDP Osakidetza no está sometida a la aplicación del régimen general del derecho público de la CAPV en materia de Tesorería, Finanzas y Contabilidad. No obstante, quiero matizar esta primera afirmación ya que la tutela del derecho público sobre entes de la naturaleza de Osakidetza es acusada.

En efecto, ambas Leyes son aplicable parcialmente al EPDP Osakidet$\mathrm{za} / \mathrm{SVS}$ respecto del resto de materias financieras como son:

- En relación a la Ley/1996, de 8 de noviembre, de Finanzas, las operaciones de endeudamiento y la prestación de garantías;

- En relación a la Ley 14/1994, de Control Económico y Contabilidad., las normas emanadas por el Departamento de Hacienda titular de las competencias en materia de contabilidad de la CAPV y, sobre todo a los efectos de consolidación de los datos contables.

- El art. 3 de la LPOHG establece que la CAPV, en ámbito de las materias propias de su Hacienda General debe actuar conforme al principio de unidad de caja, teniendo en cuenta que el art. 2.5 de la propia Ley confiere al Consejero de Hacienda la facultad de dictar disposiciones interpretativas o aclaratorias de todas las normas reguladoras de la Hacienda General del País Vasco.

\footnotetext{
${ }^{25}$ El objeto de la Tesorería General es la centralización del conjunto de recursos financieros de que dispone la Hacienda General destinados a los fines que legalmente corresponde a la Comunidad Autónoma. Integran la Tesorería, «todos los recursos financieros, sean dinero, valores o créditos, de la Administración de la Comunidad Autónoma y de sus Organismos Autónomos, así como las demás establecida por el ordenamiento vigente o relacionadas con las anteriores». Por tanto, quedan excluidas el resto de Entes que compone la Administración Institucional de la Comunidad Autónoma, esto es: los Entes Públicos de Derecho Privado, Sociedades Públicas.
} 
- Las condiciones de las cuentas de Osakidetza abiertas en entidades financieras deben cumplir los requisitos establecidos en el Acuerdo que anualmente suscribe el Departamento de Hacienda con las Entidades Financieras operantes en la CAPV. En este sentido estará sujeto a las normas generales de la Administración del CAPV.

La aplicación de las normas de derecho privado son claras en las siguientes materias:

\section{a) Tesorería}

Cada organización del Ente Público Osakidetza-Servicio vasco de salud puede disponer de su propia Tesorería, integrada por todos los recursos financieros, sean dinero, valores o créditos, por operaciones tanto presupuestarias como no presupuestarias, de los que sea titular el Ente Público en nombre de la organización respectiva.

Las funciones de cada Tesorería ingresar los derechos y pagar las obligaciones del Ente Público con cargo a la organización correspondiente, así como cualquier otra función que establezca el ordenamiento jurídico relacionada con las anteriores ${ }^{26}$.

\section{b) Ingresos de derecho privado}

Los derechos de Osakidetza lo son de derecho privado ya que de conformidad con el art. 31.2 de la LPOHG los de naturaleza pública corresponden a la Administración General y a sus Organismos Autónomos Administrativos ${ }^{27}$.

\footnotetext{
${ }^{26}$ En todo caso, corresponderá a la organización central del Ente Público, vinculando a todas las Tesorerías de las organizaciones de servicios: Dictar instrucciones sobre funcionamiento de todas las cajas y cuentas, así como supervisar la actuación de todos los gestores de las mismas. Autorizar la existencia y la supresión de cajas y la apertura y cancelación de cuentas. Concertar convenios con entidades de crédito sobre condiciones y gestión de las cuentas, siempre sin perjuicio del marco que se establezca en los convenios que suscriba el Gobierno Vasco y en función de la extensión de los mismos.

27 Se contemplan los derechos y obligaciones separadamente en los arts. 31 a 47 del LPOHG como diferentes vertientes de la Hacienda General y, por otro, se establece el régimen general de los derechos, su clasificación y las cuestiones más importantes de los ingresos, así como el régimen general de las obligaciones. Se clasifican y enumeran los derechos pertenecientes a la Hacienda General, en derechos de naturaleza pública y privada. Los primeros a su vez pueden ser ingresos de derecho público y otros derechos. Los segundos pueden ser ingresos de derecho privado y otros ingresos. La atribución a la Administración de la potestad o potestades de recaudación que incluye el procedimiento de recaudación en período voluntario y el procedimiento de apremio, supone un caso
} 
De acuerdo con lo dispuesto en el artículo 24 de la LOSE, todos los ingresos que se generen en el Ente Público como consecuencia de su actividad y, en especial, por la prestación de servicios sanitarios a terceros obligados al pago de los mismos, tendrán la consideración de ingresos de derecho privado. Por tanto, están fuera de la regulación de Ley 13/1998, de 29 de mayo, de Tasas y Precios Públicos de la Administración de la CAPV.

Los ingresos generados por el ejercicio de la actividad y prestación de servicios de Osakidetza son los denominados precios, pero que no han de confundirse con los precios públicos de la Ley 13/1998 y se rigen por el derecho privado.

\section{c) Las Transferencias que se efectúan desde la Administración General se hacen efectivas por períodos e importes proporcionales, en cuanto a las previstas para los gastos corrientes, y en el momento de cada necesidad, para las de capital, de conformidad con el art. 21 de la Ley de Finanzas}

En este sentido el art. 32 del Decreto 211/1997, de 30 de setiembre, de la Tesorería General del País Vasco, establece un procedimiento único, al margen de la naturaleza jurídica del ente administrativo ${ }^{28}$.

típico de autotutela administrativa que no puede presumirse, sino que debe estará atribuida expresamente por el ordenamiento. En el caso de la CAPV dicha potentada se atribuye a los departamentos y organismos autónomos administrativos respecto los derecho de naturaleza pública, entre los que no se encuentran los el EPDP Osakidetza/SVS. Por tanto, los derechos de Osakidetza no pueden ser hechos efectivos mediante procedimiento de recaudación, ni sujetos a dicho procedimiento en período voluntario ni ejercer el procedimiento de apremio, mientras no se atribuya mediante norma suficiente la correspondiente facultad al efecto. En definitiva, el procedimiento de cobro de los precios por los servicios prestados es el general del derecho privado. El orden jurisdiccional competente es el civil mediante los correspondientes procedimientos declarativos y ejecutivos.

${ }^{28}$ Las dotaciones que, para gastos corrientes, figuran en los Presupuestos de la Administración de la Comunidad Autónoma en favor de Organismos Autónomos, de Entes Públicos de Derecho Privado y de Sociedades Públicas, se harán efectivas por trimestres naturales anticipados, por importe equivalente a un cuarto de la dotación anual. 2.- Cuando la dotación en favor de un organismo, ente o sociedad a que se refiere el apartado anterior, sea, en importe anual, superior al 10 por 100 del presupuesto de gastos de la Administración de la Comunidad Autónoma se hará efectiva mensualmente, por importe equivalente a un doceavo de la dotación anual. En este caso, el Departamento competente en materia de tesorería podrá determinar que el pago se efectúe en más de una ocasión por mes, según los importes necesarios para sufragar los gastos de cada naturaleza. 3.- Las dotaciones que, para operaciones de capital, figuran en los Presupuestos de la Administración de la Comunidad Autónoma en favor de Organismos Autónomos, Entes Públicos de Derecho Privado y Sociedades Públicas, se harán efectivas en función de la ejecución de los programas de inversiones y teniendo en cuenta la situación de tesorería del receptor de los fondos. 
Este régimen no es el referido a subvenciones específicas (por programas generales del Departamento), las contraprestaciones por servicios prestados ni las aportaciones provenientes del contrato-programa.

\section{d) Las operaciones de endeudamiento}

Las operaciones de endeudamiento, incluida la disposición de líneas de crédito, en el Ente Público y en sus organizaciones, se encuentran sometidas al Derecho Privado, a pesar de que requieren una serie de requisitos administrativos entre los que destaca autorización previa del Departamento de Hacienda y Administración Pública ${ }^{29}$.

\section{e) Las operaciones de prestación de garantías}

Las operaciones de prestación de garantías (avales) que puedan afectar a los mismos se encuentran sometidos al Derecho Privado, Requerirán, de conformidad con lo dispuesto en el art. 51 de la Ley de Finanzas, autorización previa del Departamento de Hacienda y Administración Pública y se tramitarán, en su caso, a través de la organización central del Ente Público.

\section{f) Contabilidad}

Respecto a la contabilidad, Osakidetza se ajusta al Plan General de Contabilidad y a los principios y normas de contabilidad recogidos en la normativa mercantil, de conformidad con el art. 6.3 de la LCEC. Este Plan es el contenido en e Real Decreto 1643/1990, de 20 de diciembre, por le que se aprueba el Plan General de Contabilidad. (BOE de 27 de diciembre) ${ }^{30}$.

\footnotetext{
${ }^{29}$ El EPDP Osakidetza puede endeudarse con los límites cuantitativos que puedan establecerse en los Presupuestos Generales de la CAPV y con los requisitos que establece el art. 35 de la Ley de Finanzas citada. Esto es: 1. Que tales operaciones estén recogidas en sus respectivos presupuestos o en sus modificaciones aprobadas conforme a la legislación vigente. 2.- La realización de tales operaciones quedará limitada a las necesidades financieras de la entidad para hacer frente a las operaciones del presupuesto de capital a devengar en el ejercicio. En todo caso, sólo se podrán concertar con posterioridad a que la entidad haya recibido las transferencias de capital y a que se hayan realizado las ampliaciones de capital previstas y en sus términos. 3.- Todas las operaciones de endeudamiento a que se refiere el presente artículo requerirán autorización del Departamento de Hacienda con anterioridad a su formalización. 4.- La disposición de líneas de crédito abiertas y no utilizadas totalmente en el ejercicio anterior requerirá asimismo autorización del Departamento de Hacienda y deberán ser aplicadas a las operaciones concretas para cuya financiación fueron previstas.

${ }^{30}$ El art. 8 de la Ley 19/189, de 25 de julio, de reforma parcial y adaptación de la legislación mercantil a las Directivas de la Comunidad Económica Europea en materia de sociedades, autorizó al
} 


\section{g) Gestión Contable}

La gestión de la contabilidad se realiza a través de sus órganos conforme a lo señalado en le art. 18.4 de los Estatutos Sociales. Tanto el Ente Público Osakidetza-Servicio vasco de salud como cada una de las organizaciones que lo componen llevará su propia información económicofinanciera, elaborada de acuerdo a los criterios del Plan General de Contabilidad adaptado a las empresas de asistencia sanitaria.

No obstante, esta información económico-financiera se ajusta asimismo a lo que la normativa en materia de control y contabilidad e la CAPV, de manera que se estará al control contable de la Oficina de Control Económico del Departamento de Hacienda, a fin de asegurara y garantizar que todas las operaciones tengan el adecuado reflejo en la contabilidad ${ }^{31}$.

Gobierno para que mediante Real Decreto aprobara el Plan General de Contabilidad. La disposición final primera del Texto Refundido de la Ley de Sociedades Anónimas aprobado por el Real Decreto Legislativo 1564/1989, de 22 de diciembre, prevé la elaboración del Plan General de Contabilidad, que será de aplicación en general por todas las Empresas cualquiera que sea su forma jurídica, individual o societaria. sustituyó al aprobado por decreto 530/1973, de 22 de febrero. El Plan General de Contabilidad se estructura en cinco partes, que van precedidas por una Introducción en la que se explicitan las características fundamentales del Plan General y sus principales diferencias con el Plan de 1973. La primera parte es la relativa a los principios contables que constituyen un desarrollo de art. 38.1 del Código de Comercio. La segunda parte relativa al cuadro de cuentas, contiene los grupos, subgrupos y cuentas necesarios, debidamente codificados en forma decimal y con un título exclusivo de su contenido. La tercera parte hace referencia a las definiciones y relaciones contables y complementa el cuadro de cuentas y se describen los movimientos más usuales de la cuentas. Para algunas cuentas se incorporan criterios valorativos. La cuarta parte es la referida a las cuentas anuales de obligatoria observancia que incluye normas de elaboración de las cuentas anuales. Por último, la quinta parte es la relativa a las normas de valoración y contiene, debidamente clasificados por elementos patrimoniales, los criterios de valoración, sin perjuicio del contenido valorativo que se ha señalado para la tercera parte. $\mathrm{Al}$ mismo tiempo se introducen principios y normas de contabilidad generalmente aceptadas junto con los establecidos en la legislación mercantil, en la legislación específicamente aplicable a determinados sujetos y en el propio Plan General de Contabilidad y sus adaptaciones sectoriales, las normas de desarrollo dictadas por el Instituto de Contabilidad y Auditoría de Cuentas que serán de obligado cumplimiento.

${ }^{31}$ Las funciones del Departamento de Hacienda en materia de control contable y contabilidad en relación al Ente Público Osakidetza las podemos deducir, además del art. 4.1 de la LCEC, el art. 14 de la misma Ley, el art.21.1.b) del Decreto 173/95, de 28 de febrero, y arts. 7, 8, y 9 del Decreto 464/95, de 31 de octubre, citados anteriormente. Su facultades son: a). Inspeccionar la actividad de las oficinas de contabilidad de las entidades que componen la Administración pública de la Comunidad Autónoma de Euskadi. Junto a esta facultad genérica puede, en ese mismo ámbito, recabar la presentación y examinar las cuentas y demás documentos que hayan de rendirse al órgano de control externo u otros órganos formulando, en su caso, las observaciones que considere necesarias. b). Determinar la información de carácter contable que deben remitir las entidades del sector público de la Comunidad Autónoma, así como su periodicidad y su procedimiento de comunicación a efectos de posibilitar el ejercicio de sus funciones de centralización y elaboración de información económica y financiera del sector público. Es inherente al ejercicio del control contable la posibilidad de recabar todo tipo de información contable de las entidades del sector público, los informes eco- 


\section{III.6. Cuestiones fiscales}

La creación del Ente Público de Derecho Privado Osakidetza y la consiguiente desaparición del Organismo Autónomo Administrativo, no conlleva en principio ninguna contingencia fiscal por dicha transformación o subrogación. Ahora bien, el Ente Público es sujeto pasivo en una serie de impuestos que le son de aplicación en virtud de las normas reguladoras correspondientes. Así, respecto a los impuestos más importantes podemos decir que:

\section{A) Impuesto de Sociedades}

Conforme a lo dispuesto en los correspondientes Normas Forales de los Territorios Históricos de Alava, Bizkaia y Gipuzkoa, el Ente Público Osakidetza estará exento del Impuesto de Sociedades.

Las Normas Forales contemplan expresamente que los Entes Públicos de las Administraciones Públicas Territoriales no comprendidos en las letras anteriores (es decir, administraciones públicas territoriales, organismos autónomos y entidades autónomas de carácter administrativo, los organismos autónomos y entidades autónomas de carácter comercial, industrial, financiero o análogo, las entidades públicas encargadas de la gestión de la seguridad social) estarán exentos del impuesto salvo las sociedades públicas o estatales. A este respecto, dicha exención conlleva que no se apliquen retenciones a cuenta de dicho Impuesto en los ingresos financieros, cuestión que deberá ser advertidas por los órganos del Ente cuando se produzcan los cierres y aperturas de cuentas citados anteriormente.

\section{B) Impuesto sobre el Valor Añadido}

El Ente Público Osakidetza será sujeto pasivo del IVA en el caso de entregas de bienes y prestación de servicios. Ahora bien, dado el tipo de prestación de servicios predominante que se realizará por el Ente Público, conforme al artículo 20 apartado 1 números 2, 3 y 4 de la Ley 37/1992, del IVA, las prestaciones de servicios de hospitalización o asistencia sanitaria y las demás relacionadas directamente con las mismas realizadas por

nómico-contables que les afecten y centralizar la información contable a efectos de su consolidación y agregación. 
entidades de derecho público o por entidades o establecimientos privados en régimen de precios autorizados o comunicados están exentas del mencionado Impuesto ${ }^{32}$.

\section{c) Impuesto sobre transmisiones patrimoniales y actos jurídicos documentados}

El Ente Público Osakidetza gozará de exención subjetiva en el mencionado Impuesto según lo dispuesto en las normas forales correspondientes, dado su carácter de administración Institucional de la Comunidad Autónoma del País Vasco.

Como se puede comprobar por lo expuesto, el Ente Público mantiene un amplio conjunto de peculiaridades derivadas precisamente de su carácter de ente público que lo diferencian sustancialmente del resto de entidades netamente privadas. Es por ello que parece un tanto aventurado equipar el Ente Público Osakidetza/Servicio Vasco de Salud, con cualquier entidad privada, sin connotación pública alguna.

\section{CONCLUSIONES}

En primer lugar, Ente Público de Derecho Privado Osakidetza/SVS es un ente de naturaleza pública y un ente que forma parte de la Administración Pública de la CAPV. Ello supone la aplicación del Derecho Público en una gran parte de su actividad lo que implica el goce de las prerrogativas jurídicas generales que derivan de esa posición. Además, a ella se une su situación particular de ente gestor sanitario de la Seguridad Social en él ámbito del País Vasco.

En segundo lugar, el análisis del régimen jurídico del Ente Público de Derecho Privado Osakidetza que hemos analizado pone de relieve: la importancia relativa del régimen organizativo elegido para la gestión de la

\footnotetext{
32 Además se considerarán directamente relacionadas con las mencionadas prestaciones las que se desarrollen por servicios de alimentación, alojamiento, quirófano, suministro de medicamentos y material sanitario y otros análogos prestados por clínicas, laboratorios, sanatorios y demás establecimientos de hospitalización y asistencia sanitaria. Asimismo, dicha exención comprende la asistencia a personas físicas por profesionales médicos o sanitarios o cualquiera que sea la destinataria de dichos servicios, comprendiendo dicha exención la prestación de la asistencia médica, quirúrgica y sanitaria correspondientes al diagnóstico, prevención y tratamiento de enfermedades, análisis clínicos y exploraciones radiológicas. También están exentas la entrega de sangre, plasma sanguíneo y demás fluidos y tejidos del cuerpo humano.
} 
Seguridad Social en materia sanitaria, y que se enmarca en un proceso de reforma de la gestión del Sistema Nacional de Salud. En el trasfondo se denota una desconfianza frente al derecho público y una necesidad de introducción de las técnicas de gestión del derecho privado derivadas fundamentalmente de las conclusiones del Informe Abril.

Esta pugna se deja sentir a lo largo de a LOSE de manera que en el sustrato de la misma se observa que la terminología utilizada puede llevar a confusión sobre el límite de la aplicación del derecho público y el derecho privado. Decimos esto por que la realidad del ordenamiento jurídico de la CAPV nos indica que la mayoría del derecho aplicable al EPDP es, contrariamente a lo que pudiera parecer, el derecho público.

En tercer lugar, la personalidad jurídica de las nuevas formas de gestionar la sanidad admite muchas graduaciones jurídicas en lo relativo a la aplicación del derecho público o privado. Una determinación explícita hubiera sido más acorde con el principio de seguridad jurídica.

El mero dato de la formula jurídica de Ente Público de Derecho Privado significa poco ya que, el grado de aplicación del derecho público o privado se encuentra directamente relacionada con la Ley de creación de cada Ente y las normas que configuran su marco jurídico. No a todos los entes se le aplica las mismas normas en materia de personal, por ejemplo.

En cuarto lugar, de conformidad con la LPOHG el Ente Público de Derecho Privado Osakidetza forma parte la Administración de la Comunidad Autónoma. De este modo podemos concluir que la organización de la Administración Pública Vasca se vertebra en torno a dos ideas fundamentales: en primer lugar, la afirmación de que la Administración está integrada tanto por la Administración territorial como por las entidades institucionales referidas, dotadas de personalidad jurídica propia diferente, entre las que están los Entes como Osakidetza y en segundo lugar, que todas estas entidades integran el sector público de Euskadi. Por tanto, las prerrogativas generales que ostenta la Administración Pública le serán de aplicación, salvo norma que indique lo contrario.

En quinto lugar, la norma de creación de Osakidetza (LOSE) es la que define el ámbito jurídico privado/publico al que debe sujetarse su actuación. En nuestra opinión la separación de ambos ámbitos no se encuentra definida con al precisión deseable ya que hubiera sido más aconsejable listar las actuaciones del EPDP en uno u otro ámbito de actuación. De esa manera se hubiera evitado los problemas interpretativos a que ha dado lugar en sede jurisdiccional. 
En sexto lugar, respecto al régimen económico y hacendístico financiero tenemos: que el patrimonio está sujeto a la titularidad única depositada en la CAPV y que abarca tanto los bienes de dominio público como los de dominio privado. Por tanto, estos bienes gozan de la prerrogativa de su no ejecución y embargo. Respecto al régimen presupuestario los Presupuestos del EPDP Osakidetza/SVS forman parte y se integran en los Presupuestos Generales de Euskadi, los créditos, estructura presupuestaria, transferencias, modificaciones etc... están sujetos a las norma de régimen presupuestario de la Hacienda General y del Departamento de Hacienda. Por tanto, el Ente goza de una financiación privilegiada en función de las normas de régimen presupuestario y sus Leyes de Presupuestos que garantiza la prestación del servicio público. No estaría sujeto a los avatares económico-jurídicos de cualquier empresa elegida por el derecho privado (quiebras, suspensiones etc.).Se aplica sin reservas la Ley 13/1995, de 18 de mayo, de Contratos de las Administraciones Pública expresamente recogido en el Decreto 136/1996, de 5 de junio, sobre régimen de contratación de la Administración de la Comunidad Autónoma de Euskadi. Ello supone que Osakidetza ostenta las prerrogativas propias que las normas de la contratación pública otorgan a las Administraciones Públicas (los denominados poderes desorbitantes de la Administración: pliegos contractuales, ius variandi, interpretación, ejecución, prórrogas y extinción de los contratos entre ellos, por ejemplo).

En séptimo lugar, respecto a sus relaciones externas destaca el Contrato programa definido, desde un punto de vista del derecho formal, como convenio de carácter especial. En él se concretan, en relación con la actividad y financiación con cargo a los créditos presupuestarios públicos. El contrato-programa a pesar de su carácter de Convenio especial, es un documento administrativo y por tanto le serán de aplicación las normas y principios generales del derecho administrativo, y en cuanto acto susceptible de producir obligaciones y derechos para la Administración Pública, sujeto a diversos controles administrativos como: el control económico de carácter interventor, el jurídico etc....

De igual manera es de aplicación la Ley 30/1992 de régimen jurídicos de las administraciones Públicas y del Procedimiento administrativo común cuando ejerzan potestades administrativas. Cuando se actúa en ejercicio de potestades administrativas, se actúa en la misma posición, prerrogativas y facultades que la administración pública, por lo que la advertencia del apartado 21.2.e), relativa a la negación del carácter de órganos a las organizaciones del Ente, resulta inoperante ya que, al ser propia de la administración pública la forma organizativa a que se refiere el título II de la Ley 30/92 (órganos administrativos), y ser ésta a quien 
corresponde ejercer la competencia de modo irrenunciable. Lo mismo se predica en relación con la responsabilidad patrimonial ante terceros por el funcionamiento de sus servicios.

En octavo lugar, respecto al régimen de personal, se rigen por las propias normas establecidas en la LOSE. He aquí, que el régimen jurídico elegido para el personal del Ente es el estatutario alejado por tanto de las formas jurídicas que ofrece el derecho privado (régimen laboral) e integrado en una de las formas más características de la especialidad jurídica del personal sujeta al derecho público (límite presupuestario, límite de puestos estructurales, definición de puestos funcionales, cobertura pública etc.)

Por último, gran parte de su régimen económico y hacendístico-financiero a su régimen de organización y funcionamiento interno y a sus relaciones jurídicas externas se sujeta al derecho público y por tanto susceptibles de contar con la prerrogativas propias de toda Administración Pública. El resto de materias estarán sujetas al derecho privado y, en términos generales, podemos afirmar que las materias relativas a la tesorería (cobro de derecho, gestión de sus finanzas, Plan General de Contabilidad Pública, operaciones de endeudamiento, prestación de garantías, prescripción de derecho y obligaciones etc.) las actuaciones del Servicio Vasco de Salud estarían sujetas al derecho privado.

Por tanto, y a pesar que con toda seguridad el proyecto inicial del cambio estratégico de la sanidad vasca pretendió ir más lejos con el EPDP, no tuvo más remedio que ir ciñéndose a las normas básicas que desde el Estado fueron dictándose tales como: la Ley de Contratos del Estado, el proyecto de Estatuto Marco, ciertas normas básicas de la Ley General Presupuestaria y otras normas de la Organización de los entes público.

Ello no obsta para que el modelo de gestión de la sanidad pública vasca se haya constituido en un referente tanto para el INSALUD como pare el resto de CCAA con competencias en sanidad. La descentralización y la dotación de nuevas e innovadoras fórmulas en la gestión contenidas en la LOSE y sus normas desarrollo permiten la utilización del derecho privado, en aquellas parcelas necesitadas de una mayor agilidad de cara al exterior. Pero al mismo tiempo no huye del derecho público ya que queda garantizada su aplicación allí donde estimamos se precisa y, en especial, al concebir el servicio sanitario como interés general protegido, precisamente, por las normas de derecho público que hemos analizado. 
En fin, la utilización por parte de las Administraciones sanitarias de personificaciones privadas o sometimiento al Derecho privado no puede obviar el dato insoslayable del carácter público de la prestación sanitaria.

\section{BIBLIOGRAFÍA}

AAVV.: «Transferencia a las Comunidades Autónomas en materia de sanidad». Ed. Dirección General de la Alta Inspección y Relaciones con las Administraciones Territoriales. Ministerio de Sanidad y Consumo. Madrid, 1989.

- «Seminario sobre la distribución entre las Comunidades Autónomas de los recursos públicos de la Sanidad», Ed. IEA de la Generalitat de Catalunya.

AAVV: «La organización de la salud pública: su reforma en las reformas», en Informe SESPAS 1998: La Salud Pública y el Futuro del Estado del Bienestar. Ed. Escuela Andaluza de salud Pública, Granada, 1998.

Argente i M. Giralt: «El presupuesto y el control del gasto» en Presupuesto y Gasto Público, n. ${ }^{\circ}$ 10/1993.

- «Economía y gestión sanitaria en España. Aportaciones para el debate».- Les reformes del sistema de financament de la sanitat2 en Fulls Economics del sistema Sanitari, n. ${ }^{\circ}$ 23, 1994.

G. Ariño Ortiz, y J.M. Sala Arquer: «La gestión de los Servicios Sanitarios mediante formas personificadas: especial referencia a empresas públicas y sociedades», en Tercer Congreso de Derecho y Salud bajo el título de la Gestión de los Servicios sanitarios: Modelos Alternativos. Ed. Gobierno de Navarra, Departamento de Salud. 1995.

J.A. ARRATIBEL ARRONDO: «Eusko Jaurlaritzako Aurrekontuaren Finantzaketa: 1997-2001 artean Foru aldundiek egin beharreko ekarpenen araudia.» Revista Vasca de Administración Pública, n. ${ }^{\circ}$ 48, mayo-agosto 1997. IVAP-HAEE Vitoria-Gasteiz.

- «Euskal Herriogasuntza Nagusiaren finantzaketarako arazoak: irtenbide juridiko baten azterketa». n. ${ }^{\circ}$ 1/97 de la revista Jurídica Euskal Legelarien Aldizkaria de la Sociedad de Estudios Vasco-Eusko Ikaskuntza. Donostia 1997. 
- «La nueva ordenación sanitaria de Euskadi como medida frente a la crisis de la administración prestacional y de financiación del gasto sanitario», en la Revista Jurídica La Ley, n. ${ }^{\circ}$ 4540, AÑO XIX. Sección doctrina. Madrid.1998.

— «Euskadiko Osasun Antolamenduari buruzko 8/1997 Legea: osasun gastua eta Ongizte estatuaren egonkortasuna», en revista Jurídica Euskal Legelarien Aldizkaria de la Sociedad de Estudios Vasco-Eusko Ikaskuntza n. ${ }^{\circ}$ 3. San Sebastián-Donostia 1998.

- «Euskal osasun-sistemaren finantzaketa, aurrekontua eta kontrol ekonomikoaren azterketa:osasun antolamenduari buruzko 8/1997 Legearen irakurketa». En Revista Vasca de Administración Pública, n. ${ }^{\circ} 52$ (setiembre-diciembre), 1998.

- «El marco jurídico sanitario vasco como respuesta a la crisis del Estado de Bienestar: ordenación y control del gasto sanitario», en Revista Derecho y Salud. Asociación de Juristas de la Salud. Barcelona, 1999.

- «Características Jurídicas del control financiero de las Administraciones Vascas: especialidad del control del gasto sanitario», en la Revista Jurídica La Ley, n. ${ }^{\circ}$ 4906, AÑO XX. Sección doctrina. Madrid.1999.

— «El control financiero y de gestión del gasto sanitario en Euskadi», en Revista Auditoria Pública n. ${ }^{\circ} 19$ (Diciembre 1999). Ed. Revista de los Organos Autonómicos de Control Externo. Pamplona, 1999.

J.A. Arratibel Arrondo y Ma.S. Gómez de Arian: «La aplicación de la prerrogativas jurisdiccionales en el proceso laboral a Entes Institucionales Sanitarios: el caso del Servicio Vasco de Salud-Osakidetza», en la Revista Jurídica La Ley, n. ${ }^{\circ}$ 4968, AÑO XXI. Sección doctrina. Madrid.2000.

M. Bassols Coma: «La contratación Administrativa en le marco de la Seguridad Social», en Libro homenaje a J. Gónzalez Pérez. Ed. Civitas. Madrid.

I. BorRajo InIESTA: «La huida hacia fórmulas de gestión de Derecho Privado en la prestación e Servicios sanitarios: la supuesta crisis del Derecho Administrativo» en Tercer Congreso de Derecho y Salud bajo el título de la Gestión de los Servicios sanitarios: Modelos Alternativos. Ed. Gobierno de Navarra, Departamento de Salud. 1995. 
J.M. CABASES HitA: «Los condicionantes económicos en la evolución de los modelos de gestión de los servicios sanitarios» en Tercer Congreso de Derecho y Salud bajo el título de la Gestión de los Servicios sanitarios: Modelos Alternativos. Ed. Gobierno de Navarra, Departamento de Salud. 1995.

- «La financiación de la sanidad en España», en Informe SESPAS 1998: La Salud Pública y el Futuro del Estado del Bienestar. Ed. Escuela Andaluza de salud Pública, Granada, 1998.

R. CANTERo Rivas: «Las nuevas formas de gestión de los servicios sanitarios y sociosanitarios» en Revista Jurídica de doctrina y Jurisprudencia «La Ley». Diario 4544 de 20 de mayo de 1998.

C.J. FERNÁNDEZ-CARNICERo y GónZALEZ: «Las nuevas formas de personificación de los entes públicos. Su dimensión institucional y jurídica en le Derecho Comparado» en XLI Semana de estudios de Derecho Financiero. Ed. Estudios de Hacienda Pública. Instituto de Estudios Fiscales. Ministerio de economía y Hacienda. Madrid, 1997.

R. FERNÁdez Cuenca: «Análisis de los servicios sanitarios», en Informe SESPAS 1998: La Salud Pública y el Futuro del Estado del Bienestar. Ed. Escuela Andaluza de salud Pública, Granada , 1998.

J.M. Fernádez Pastrana: «El Servicio público de la sanidad: el marco constitucional», Madrid, Civitas, 1984.

S. GARCía IzQUiERDO: «Las nuevas formas de personificación de los Entes Públicos: Experiencia en la Administración Económica y Finaciera», en XLI Semana de estudios de Derecho Financiero. Ed. Estudios de Hacienda Pública. Instituto de Estudios Fiscales. Ministerio de Economía y Hacienda. Madrid, 1997.

F. GARRIDO FALLA: «La administrativación de la gestión de la Seguridad Social» en Revista de Administración Pública, 140, 1996.

GobIERNo VASCO: «Osasuna Zainduz. Estrategias de cambio para la Sanidad Vasca.» Ed. Servicio Central de Publicaciones del Gobierno Vasco. Vitoria-Gasteiz, 1993.

C. LAmbarri y J.Z. LarRea de J.L. Vicuña: «El Cupo». Ed. IVAP-HAEE, Oñati, 1994.

López i G. Casasnovas, Corona i J. F. Ramón y Figueres i J. Marimont: «Estudi del sistema de financament autonomic de la sanitat» en Collec- 
ció Els Llibres dels Fulls Economics, n. ${ }^{\circ}$ 3. Deparatment de sanitat i Seguritat Social, Generalitat de Catalunya, 1992.

J.J. MARTín MarTín: «Cambio e innovación institucional. Las nuevas experiencias en gestión sanitaria» en Informe SESPAS 1998: La Salud Pública y el Futuro del Estado del Bienestar. Ed. Escuela Andaluza de salud Pública, Granada, 1998.

E. Montoya Martín: «Las empresas públicas sometidas al Derecho Privado». Ed. Marcial PONS. Ediciones Jurídicas y sociales, SA. Madrid, 1996.

S. MuÑOZ MACHADO: «La formación y la crisis de los servicios sanitarios públicos». Ed. Alianza Editorial, Madrid, 1995. -«Los condicionantes normativos en la evolución de los modelo de gestión de los Servicios Sanitarios» en Tercer Congreso de Derecho y Salud bajo el título de la Gestión de los Servicios sanitarios: Modelos Alternativos. Ed. Gobierno de Navarra, Departamento de Salud. 1995.

V. ORTÚN RUBIO: «Sistema sanitario y Estado del Bienestar: problemas a la vista», en Informe SESPAS 1998: La Salud Pública y el Futuro del Estado del Bienestar. Ed. Escuela Andaluza de salud Pública, Granada, 1998.

A. Panizo García: «Régimen Jurídico de los Convenios de Colaboración» en revista La Ley, 24/10/1996, n. ${ }^{\circ} 3895$.

J. Peman Gavin: «Derecho a la salud y administración sanitaria», Bolonia, Publicaciones del Real Colegio de España, 1989.

Revista «Diario Médico» de fecha 2-IX-1996 «Diario Médico de 9-II1999, p. 10.

J.L. Uriarte Santamaria: en «Ley de Principios Ordenadores de la Hacienda General del País Vasco». Colección Parlamento Vasco.

F. VILLAR RoJAS: «La Ley de habilitación de nuevas formas de gestión del Sistema nacional de Salud: ¿Hacia la desregulación de la Sanidad Pública? En Derecho y Salud, Publicación Oficial de la Asociación de Juristas de la Salud, Volumen 6, número 2, (Julio/Diciembre 1998.

- «La huida al derecho privado en la gestión de los servicios de salud» en Revista Derecho y Salud, n. ${ }^{\circ}$ 2-2, 1994. 
- «La Responsabilidad de las Administraciones Sanitarias: fundamento y límites2. Ed. Praxis. Barcelona, 1996. -2 Privatización de servicios públicos». Ed. Tecnos, Madrid 1993. 